\title{
Prediction of a Mei-yu Frontal Cyclone and the Associated Torrential Rainfall over Southern Taiwan During 2008 Mei-yu Season
}

\author{
Hsi-Chyi Yeh $^{1, *}$ and Shui-Shang $\mathrm{Chi}^{2}$ \\ ${ }^{1}$ Center for General Education, Aletheia University, New Taipei City, Taiwan \\ ${ }^{2}$ Central Weather Bureau, Taipei, Taiwan
}

Received 2 May 2012, accepted 3 September 2012

\begin{abstract}
A torrential rain episode ( $\geqq 200 \mathrm{~mm} \mathrm{day}^{-1}$ ) was observed over coastal regions of southern Taiwan (south of $23.0^{\circ} \mathrm{N}$ ) on 5 June 2008 under the influence of a meso-scale frontal cyclone (MFC) formed along the western flank of a Mei-yu frontal zone. Through the incorporation of additional observations over the ocean collected during Southwest Monsoon Experiment (SoWMEX)/Terrain-influenced Monsoon Rainfall Experiment (TiMREX), the location of a Mei-yu frontal boundary, defined by the wind shift, is better identified over the open ocean by the data assimilation of dropsonde observations. Meanwhile, the low-level cyclonic vorticity and horizontal convergence are increased along the Mei-yu frontal zone, and an increment maximum center of cyclonic vorticity locates over the north of South China Sea (SCS), where the MFC subsequently forms.

For the development and maintenance of a MFC over the northern SCS, the additional data assimilation, using the combination of the dropsonde and the radar radial velocity, has significantly improved the prediction of an MFC with a best track over the open ocean. Therefore, the daily rainfall distribution and amount over southern Taiwan are reproduced and significantly improved, particularly using dropsonde observations combined with the radar radial velocity.
\end{abstract}

Key words: Torrential rain, Mei-yu, SoWMEX/TiMREX, Data assimilation

Citation: Yeh, H. C. and S. S. Chi, 2013: Prediction of a Mei-yu frontal cyclone and the associated torrential rainfall over southern Taiwan during 2008 Mei-yu season. Terr. Atmos. Ocean. Sci., 24, 69-87, doi: 10.3319/TAO.2012.09.03.01(A)

\section{INTRODUCTION}

Flash flooding and debris flow resulting from heavy rainfall have become the most important issue associated with natural disasters in Taiwan during the warm season (May-August). Heavy rain events across diverse locations around the globe may share essential similarities. In general, Ramage (1971) suggested that heavy rain storms are associated with synoptic-scale systems, draw on a plentiful supply of moisture, and are usually anchored by a discontinuity in surface roughness, generally a coastline or a mountain range.

In Taiwan, previous studies on heavy rainfall ( $\geqq 130$ $\mathrm{mm}$ day $^{-1}$ ) episodes during the Mei-yu season (mid-May to mid-June) using the data from the 1987 Taiwan Area Mesoscale Experiment (TAMEX) (Kuo and Chen 1990) are concentrated on the windward regions of the Central

\footnotetext{
* Corresponding author

E-mail:au4172@mail.au.edu.tw
}

Mountain Range (CMR) under the prevailing southwesterly monsoon flow; i.e., in the west-to-northwest of Taiwan. Most of the heavy rainfall during TAMEX are related to the passage of Mei-yu frontal systems (Chen et al. 1989; Chen and Hui 1990; Trier et al. 1990; Ray et al. 1991; Li et al. 1997; Yeh and Chen 1998; Yeh et al. 2002), orographic effects (Chen 1992; Li et al. 1997; Yeh and Chen 2002), and local circulations (Johnson and Bresch 1991; Yeh and Chen 2004). Also, the trough, divergence and cold-core low in the upper level are important forcing to collocate with the low-level forcing and to produce heavy rain over Taiwan (Chen and Li 1995; Li et al. 1997; Yeh and Chen 1998). In addition, the low-level jet (LLJ) is a typical feature within the warm sector of TAMEX fronts (Chen and Chen 1995). Chen and $\mathrm{Yu}$ (1988) suggested that a well-defined low-level jet (LLJ) which developed in the $850-700 \mathrm{hPa}$ layer was an important feature frequently accompanying heavy rain events. The LLJ transported warm, moist air from the south 
in low levels to generate convective instability (Chen 1983) which was favorable for the development of widespread precipitation over Taiwan and southern China, especially under the influence of upper-level forcing (Chen and $\mathrm{Li}$ 1995; Li et al. 1997). Furthermore, mesoscale convective systems, such as squall lines (Lin et al. 1990; Wang et al. 1990; Chen 1991; Tao et al. 1991) and rainbands (Li et al. 1997) embedded in frontal systems, frequently developed over the Taiwan Strait and produced heavy rainfall over Taiwan as they moved inland. In contrast to western Taiwan, a climatologically unusual case of heavy rain events $\left(>300 \mathrm{~mm} \mathrm{day}^{-1}\right.$ ) observed in northeastern Taiwan on 28 May 2001 has been studied by Yeh and Chen (2004) using the National Aeronautics and Space Administration's (NASA) Quick Scatterometer (QuikSCAT) ocean surface winds. The retrogression of a Mei-yu front over the nearby ocean of eastern Taiwan collocated with a short-wave trough in upper levels provide favorable large-scale conditions for the production of localized heavy rainfall. In addition, latent heating has been suggested to be responsible for the retrogression of the Mei-yu front and the development of a surface frontal cyclone over ocean east of Taiwan (Yeh and Chen 2004).

In order to forecast the potential for the debris flow caused by heavy rainfall over the Taiwan area, the Central Weather Bureau (CWB) has defined new categories for measuring heavy rainfall, torrential and extremely torrential rainfall using the 24-hr accumulated rainfall greater than 130,200 , and $350 \mathrm{~mm}$ respectively. Based on weather and statistical rainfall analyses during the Taiwan Mei-yu season, the heavy rainfall is frequently produced in southwestern Taiwan (Chen et al. 2007), while mesoscale convective systems (MCSs) embedded within the southwesterly monsoon flow and the Mei-yu front are primarily responsible for the production of the rainfall there (Chen and Chen 2003) under favorable large-scale conditions and the orographic effects (Chen et al. 2005, 2007). Some weather analyses also have revealed that rain-producing systems that cause heavy rainfall over southwestern Taiwan originate from the ocean near the southwest coast of Taiwan or form in the north of South China Sea (Chen et al. 2005, 2010). However, the prediction of the heavy rainfall over coastal regions of Taiwan related to mesoscale rain-producing systems triggered along Mei-yu frontal system are quite challenging, because the evolution and propagation of a mesoscale rain system over the open ocean at most cases cannot be captured completely by numerical modeling under limited traditional observations.

During the course of the Southwest Monsoon Experiment (SoWMEX)/Terrain-influenced Monsoon Rainfall Experiment (TiMREX) from May - June 2008 (Jou et al. 2010), additional datasets were collected, including Doppler radar data, dropsonde observations from the aircraft, retrieved atmospheric profiles from the FORMOSAT-3/
Constellation Observing System for Meteorology, Ionosphere and Climate (COSMIC) project, and QuikSCAT ocean surface winds. One of the objectives during SoWMEX/TiMREX was to improve the capability of heavy rain now-casting and quantitative precipitation forecasting in Taiwan. During the 2008 Taiwan Mei-yu season, a torrential rain episode on 5 June occurred over southern Taiwan (south of $23.0^{\circ} \mathrm{N}$ ), distributed in the southeastern and southwestern coastal regions (Fig. 1). Via observational analysis, Lai et al. (2011) examined a subtropical oceanic meso-scale convective vortex (MCV) over the South China Sea (SCS), including the associated environmental features and the kinematic and thermodynamic structure of the MCV with an embedded strong inner subvortex. Using visible satellite images, a MCV and a cloud eddy embedded within a mesoscale frontal cyclone (MFC) along the Mei-yu frontal zone are further analyzed by Chi and Huang (2011). The results reveal that the MCV forms over the north of the SCS around 2157 Universal Coordinated Time (UTC) on 4 June. It moved southward and then eastward to approach the offshore in the west of southern Taiwan around 0957 UTC on 5 June. Meanwhile, the center of the MCV coincides with that of the MFC during the daytime hours on 5 June. In this study, additional data collected during 2008 SoWMEX/ TiMREX are used to further identify a primary weather system, such as a Mei-yu front over the ocean surrounding southern Taiwan, and to predict a MFC developed along

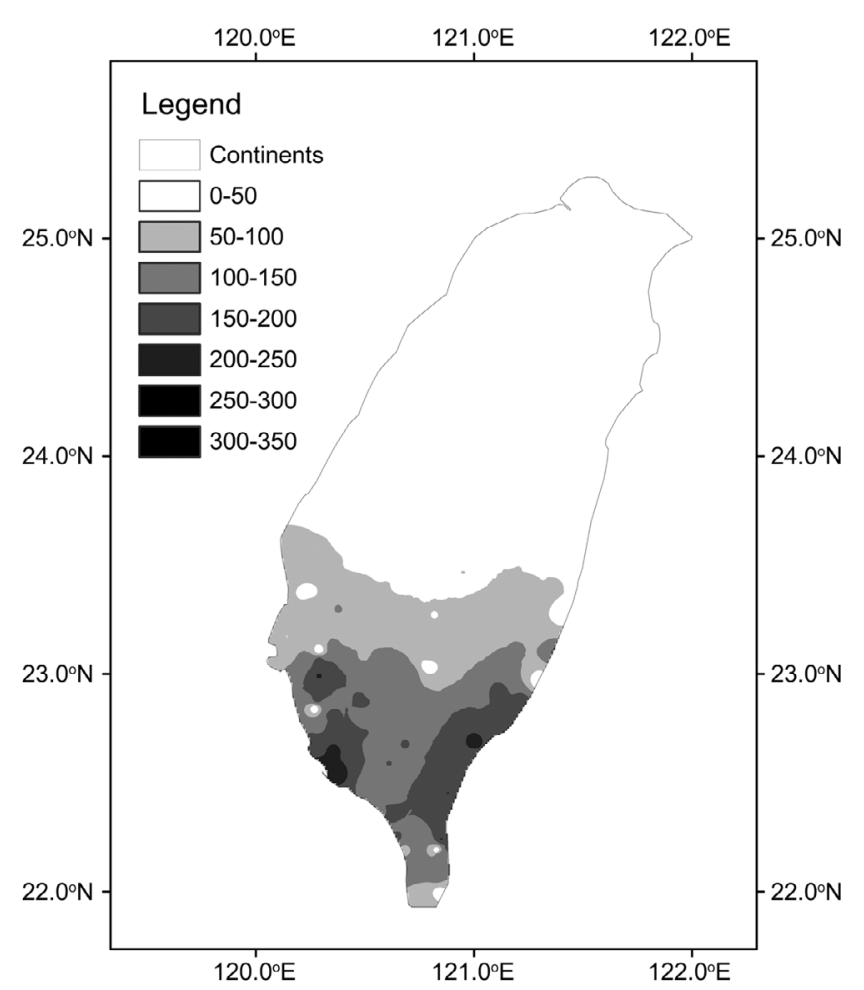

Fig. 1. Daily rainfall distribution on 5 June 2008. The rainfall amount (grey) with 50-mm intervals. 
the Mei-yu frontal zone over the north of the SCS. Also to improve the prediction of associated torrential rainfall over southern Taiwan on 5 June is conducted.

For this torrential rain episode, the weather conditions are analyzed in section 1. Additional data and the methodology Weather Research and Forecasting (WRF) model and the associated three-dimensional variational (3D-Var) data assimilation system as well as statistical method are briefly introduced in section 2. To identify the Mei-yu frontal boundary and the prediction of a MFC is revealed in sections 3 and 4. And the impact of different combinations from additional datasets on the prediction of torrential rainfall over southern Taiwan is presented in sections 5. Major results are summarized in section 6 .

\section{WEATHER CONDITIONS}

A torrential rain event with daily rainfall maxima greater than $200 \mathrm{~mm}$ was observed over southeastern and southwestern coastal regions of Taiwan on 5 June 2008 (Fig. 1) under the influence of a Mei-yu frontal system and a MFC (Fig. 2). The surface front moved southward and reached southern Taiwan at 0000 UTC on 4 June (Fig. 2a). It passed through southern Taiwan $12 \mathrm{hr}$ later and then remained stationary over the Bashi Channel north of the Philippines (not shown). As subjectively analyzed by the CWB of Taiwan, a MFC was revealed over the north of SCS at 0000 UTC on 5 June (Fig. 2b), while the infrared (IR) satellite imagery (Fig. 3) showed that the convection associated with the MFC develop in the western flank of the Mei-yu frontal system on the evening of 4 June (Figs. 3a and b). At 0000 UTC on 5 June, the convection associated with the MFC was located over southern Taiwan and closed to the ocean (Fig. 3c). Weak rainfall was observed over southern Taiwan. At 1200 UTC, the convection mainly covered the eastern area of southern Taiwan (Fig. 3d). Thus, torrential rain- fall was observed over southern Taiwan and was produced primarily in the time slot between 0000 UTC and 1200 UTC on 5 June. During the development of a MFC, the $500-\mathrm{hPa}$ upper level trough propagated over the open ocean, east of Taiwan and dissipated (not shown) when significant rainfall was produced over southern Taiwan.

Based on the soundings taken at Ton-kung (46750) (Fig. 4) over southern Taiwan from 1800 UTC on 4 June to 1800 UTC on 5 June, the atmospheric environment showed a near-neutral condition and the environmental moisture content increase with higher equivalent potential temperature during the rainfall period (0000 UTC - 1200 UTC) on 5 June. Meanwhile, the low-level winds strengthen significantly at 0000 UTC [0800 local standard time (LST)] and turn to the southerly-to-southeasterly (Fig. 4) during the daytime hours. After the advent of torrential rainfall, the low-level winds change to the westerlies at 1200 UTC (2000 LST) and the atmosphere subsequently became drier over southern Taiwan.

\section{DATA AND METHODOLOGY}

\subsection{Data}

Recall that additional atmospheric datasets were collected during the 2008 SoWMEX/TiMREX, including Cigu Doppler radar data (cg), dropsondes from aircraft observations (drp), FORMOSAT-3/COSMIC retrieved atmospheric profiles (gps), and QuikSCAT ocean surface winds (qk) data (Fig. 5a). Here the cg, drp, gps and qk is used to symbolize four different datasets respectively. In this study, these data are utilized in weather analyses related to a Mei-yu frontal system, and the prediction of a MFC as well as torrential rainfall over southern Taiwan on 5 June 2008. In addition, the rainfall data from 399 rainfall stations (Fig. 5b) were exploited to reveal the daily rainfall distribution and validate the rainfall prediction. (a)

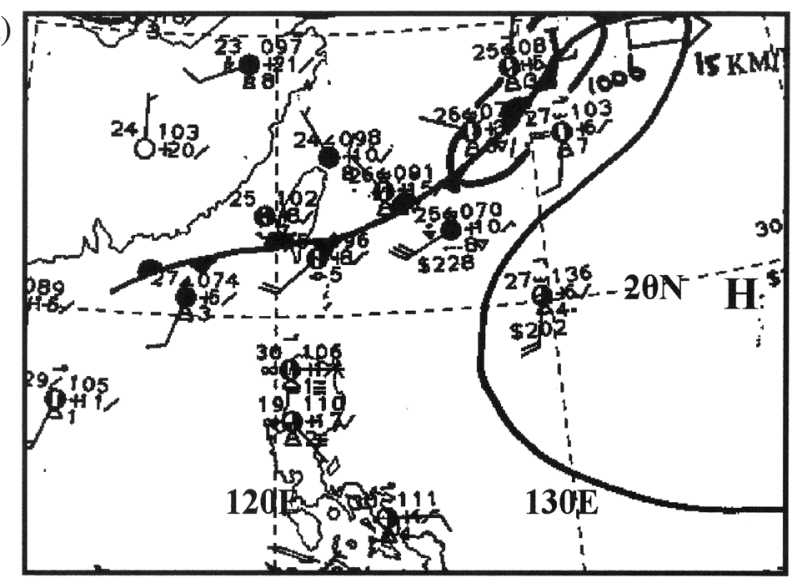

(b)

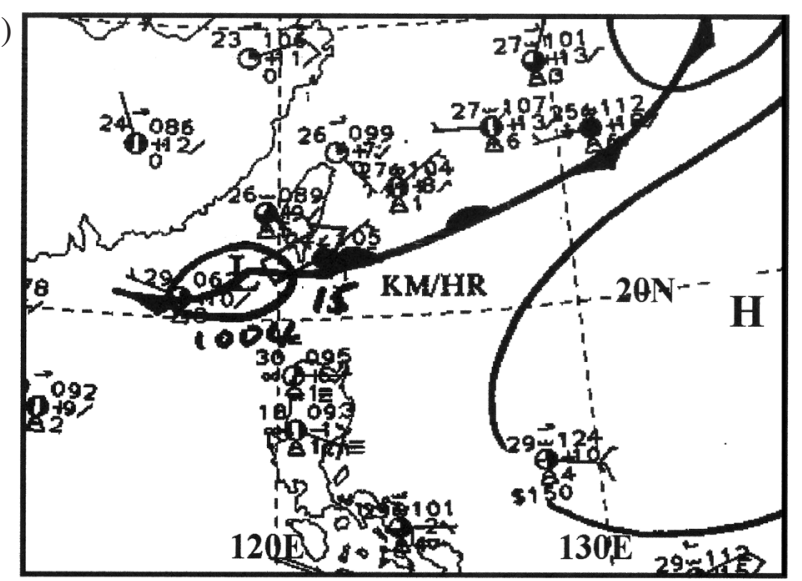

Fig. 2. Surface weather analysis (a) at 0000 UTC on 4 June and (b) at 0000 UTC on 5 June 2008 from the Central Weather Bureau (CWB) of Taiwan. 

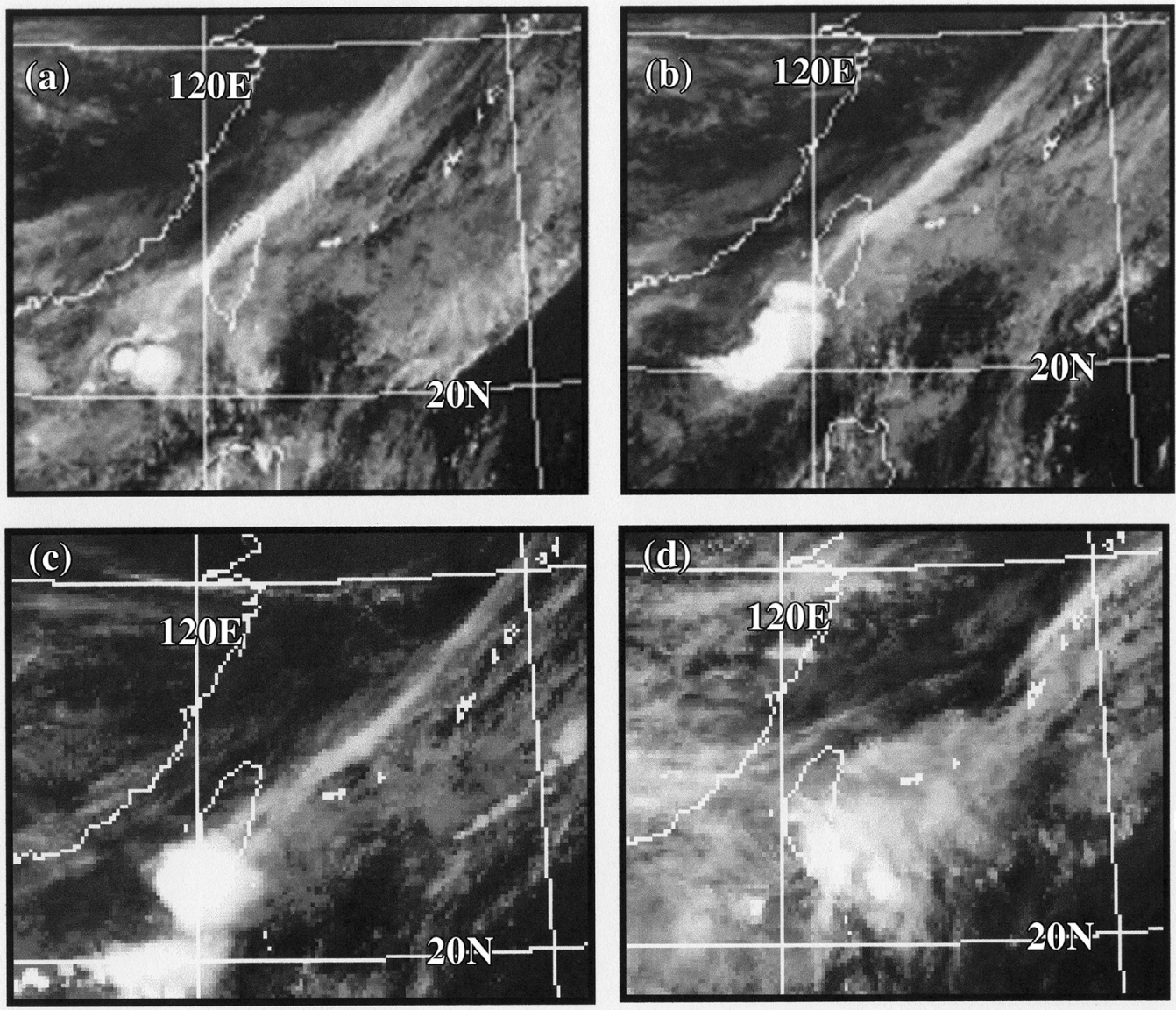

Fig. 3. IR satellite imagery (a) at 1800 UTC on 4 June, (b) at 2100 UTC on 4 June, (c) at 0000 UTC on 5 June, and (d) at 1200 UTC on 5 June 2008 from the Central Weather Bureau of Taiwan.

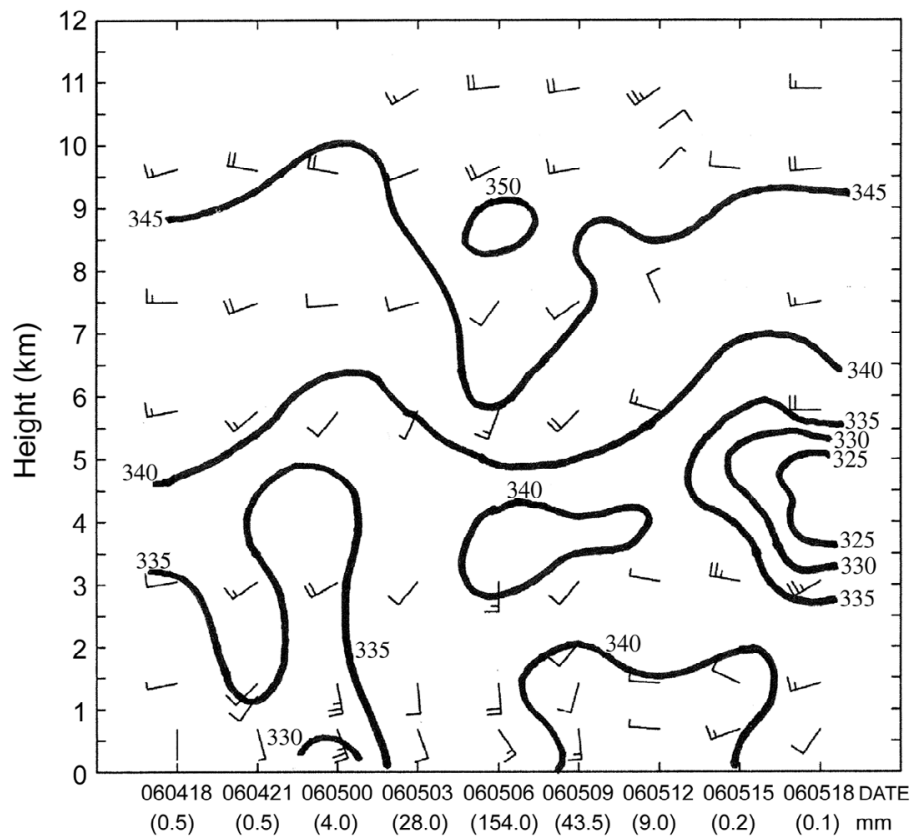

Fig. 4. Time series in the vertical profile of equivalent potential temperature (solid line) and wind barbs based on sounding 46750 over southern Taiwan from 1800 UTC on 4 June to 1800 UTC on 5 June 2008. Equivalent potential temperature has $5^{\circ} \mathrm{k}$ intervals. The full and half barbs represent 5 and $2.5 \mathrm{~m} \mathrm{~s}^{-1}$, respectively. The observed 3-hr accumulated rainfall at CWB rain gauge $\left(22.57^{\circ} \mathrm{N} ; 120.31^{\circ} \mathrm{E}\right)$, south of the sounding 46750 , is shown below the date axis. 

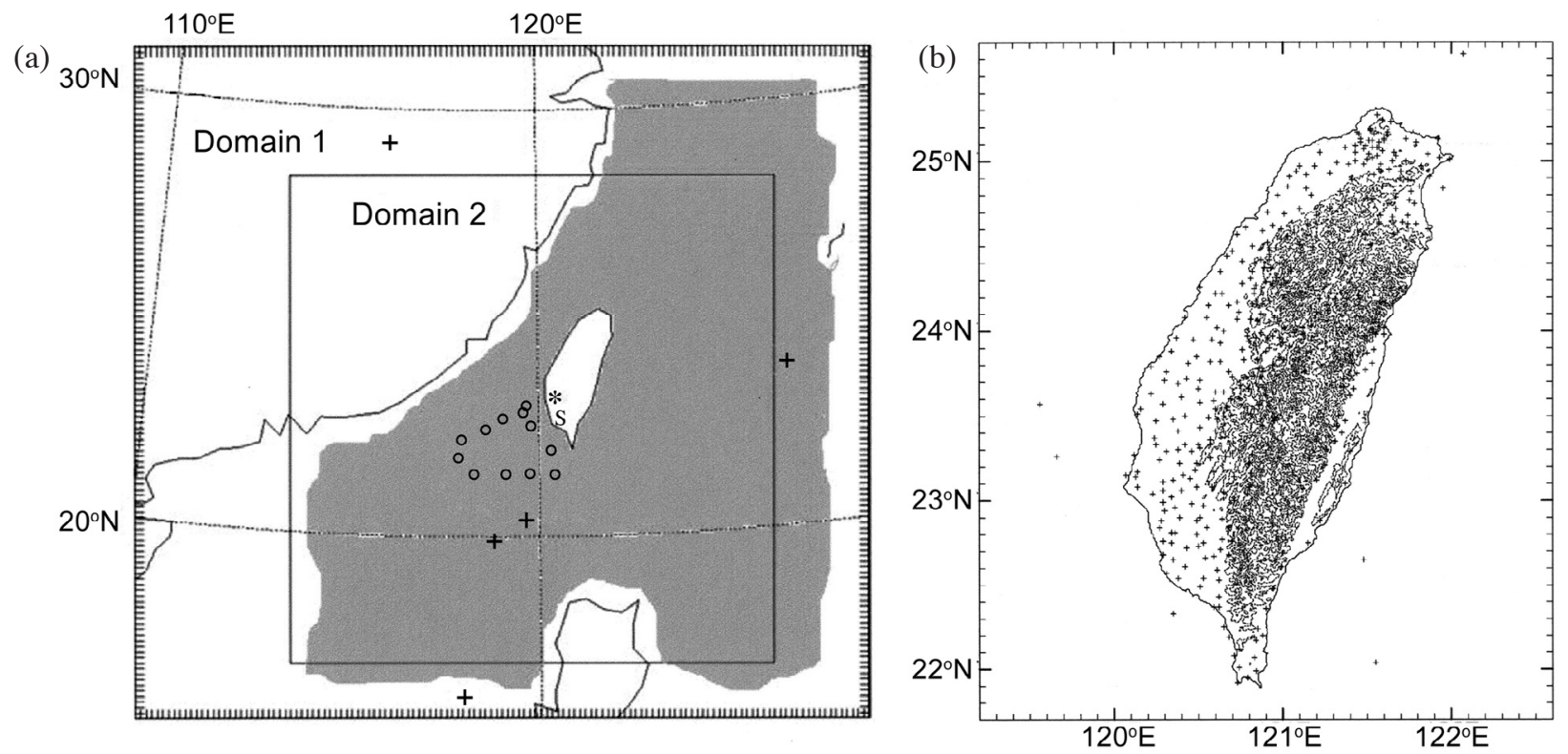

Fig. 5. (a) Model domains with 15- and 5-km horizontal resolutions for the coarse domain and nested domain. The location for the Cigu Doppler radar $(*)$, dropsonde observations (o), Formosa \#3/COSMIC atmospheric profiles (+), QuikSCAT oceanic winds (shaded) and sounding 46750 (s) are presented. (b) 399 rainfall stations (+) from CWB. The terrain height greater $500 \mathrm{~m}$ is plotted.

\subsection{The Mesoscale Model and the Associated 3D-Var System}

To reveal the characteristics of a torrential rainfall event on 5 June 2008 over southern Taiwan with additional observations, the Advanced Research WRF (ARW) mesoscale model (Skamarock et al. 2008) and WRF 3D-Var system version 2 were utilized. This system was developed from MM5 3D-Var (Barker et al. 2004) and used in many WRF data assimilations (e.g., Xiao and Sun 2007; Xiao et al. 2009; Yeh 2010).

In the vertical, the ARW model has thirty-one sigma levels (Table 1) from the surface $(\sigma=1.0)$ to $50 \mathrm{hPa}(\sigma=$ $0.0)$. A fine domain with $5-\mathrm{km}$ grid-spacing is nested within a coarse domain with $15-\mathrm{km}$ grid spacing. The ARW model physics include planetary boundary layer (PBL) processes with the Yonsei University scheme (Skamarock et al. 2008), short-wave radiation (Dudhia 1989) and long-wave radiation (Mlawer et al. 1997), land surface physics (Chen and Dudhia 2001), and precipitation physics. The precipitation is calculated by both the explicit scheme with mixed-phase processes (Ferrier et al. 2002) and the parameterization of the Betts-Miller-Janjić scheme (Janjić 1994, 2000) for the coarse domain. For the nested domain, the precipitation is calculated directly by the explicit scheme using mixedphase processes (Ferrier et al. 2002).

To produce the optimal initial conditions for a numerical weather prediction, the WRF 3D-Var system (Barker et al. 2004) is used to assimilate additional datasets within model domains (Fig. 5). The 3D-Var system determines the analysis vector $\mathbf{x}$ by minimizing the cost function $\mathrm{J}(\mathbf{x})$, defined as

$\mathrm{J}(\mathbf{x})=1 / 2\left(\mathbf{x}-\mathbf{x}^{\mathrm{b}}\right)^{\mathrm{T}} \mathbf{B}^{-1}\left(\mathbf{x}-\mathbf{x}^{\mathrm{b}}\right)+1 / 2\left(\mathbf{y}-\mathbf{y}^{\mathrm{o}}\right)^{\mathrm{T}}(\mathbf{E}+\mathbf{F})^{-1}\left(\mathbf{y}-\mathbf{y}^{\mathrm{o}}\right)$

In Eq. (1), the analysis vector, $\mathbf{x}$, consists of the model variables, wind components, temperature, pressure perturbation, and mixing ratio of water vapor, all at the model levels. The vector $\mathbf{x}^{\mathrm{b}}$ is the background information first guess,

Table 1. Vertical thirty-one sigma levels for the ARW model.

\begin{tabular}{cccccc}
\hline Level & Sigma $(\boldsymbol{\sigma})$ & Level & Sigma $(\boldsymbol{\sigma})$ & Level & Sigma $(\boldsymbol{\sigma})$ \\
\hline 1 & 1.000 & 12 & 0.786 & 23 & 0.290 \\
2 & 0.993 & 13 & 0.753 & 24 & 0.236 \\
3 & 0.980 & 14 & 0.718 & 25 & 0.188 \\
4 & 0.966 & 15 & 0.680 & 26 & 0.145 \\
5 & 0.950 & 16 & 0.639 & 27 & 0.108 \\
6 & 0.933 & 17 & 0.596 & 28 & 0.075 \\
7 & 0.913 & 18 & 0.550 & 29 & 0.046 \\
8 & 0.892 & 19 & 0.501 & 30 & 0.021 \\
9 & 0.869 & 20 & 0.451 & 31 & 0.000 \\
10 & 0.844 & 21 & 0.398 & & \\
11 & 0.816 & 22 & 0.345 & & \\
\hline
\end{tabular}


which is taken from the National Centers for Environmental Prediction (NCEP) global forecasting system (GFS); B is the background error covariance matrix, which was derived from one-month WRF forecasts data with the National Meteorological Center (NMC) method (Parrish and Derber 1992). Here the background error covariance matrix is the default of the $3 \mathrm{D}-$ Var system; $\mathbf{y}^{\circ}$ is the observation vector and $\mathrm{y}$ is the equivalence of the observations transformed from the analysis vector $\mathbf{y}=\mathrm{Hx} ; \mathbf{E}$ and $\mathbf{F}$ are the (instrumental) observations and representative error covariance matrices, respectively. The representative error is an estimate of inaccuracies introduced in the observation operator $\mathrm{H}$.

In addition, the WRF 3D-Var system uses an incremental approach. With certain dynamic/physics constraints, such as hydrostatic assumption, cyclostrophic/geostrophic balance, etc., the control variables in this system are the increments of stream function, potential velocity, unbalanced pressure, and mixing ratio/relative humidity. The analysis from the 3D-Var system can be an optimal combination of the observation information $\left(\mathbf{y}^{\circ}\right)$, prior statistics $(\mathbf{B}, \mathbf{E}, \mathbf{F})$, and the dynamics/physics. As will be shown in section 4, the assimilation of the additional observations produces increments in the kinematic field through the dynamical/ physical constraints. Here, additional observed data around 0000 UTC on 4 June will be assimilated with global data provided from the NCEP/GFS to generate model initial conditions, which can be used to identify the Mei-yu frontal boundary, predict a MFC over the north of SCS and daily rainfall distribution over southern Taiwan on 5 June. The combinations with/without data assimilation by additional datasets and NCEP/GFS global data for weather predictions are listed in Table 2.

\subsection{Statistical Method}

A statistical measure is utilized to quantify the improvement in the prediction of daily regional rainfall over Taiwan on 5 June. Note that this torrential rainfall event is produced over southern Taiwan and the maxima of the daily rainfall are distributed over southwestern and southeastern coastal regions (Fig. 1). The statistical method, root-mean squared error (RMSE) (Wilks 2006) shown in Eq. (2) is conducted to simply evaluate the performance in the predicted daily rainfall over southern Taiwan and the associated low-level wind field and relative humidity.

RMSE $=\left[\frac{\sum_{\mathrm{i}=1}^{\mathrm{N}}\left(\mathrm{F}_{\mathrm{i}}-\mathrm{O}_{\mathrm{i}}\right)^{2}}{\mathrm{~N}}\right]^{1 / 2}$

In Eq. (2), $\mathrm{F}_{\mathrm{i}}$ and $\mathrm{O}_{\mathrm{i}}$ refer to forecast and the observations for the point (time) i respectively, and the summation is over the number point (time) N. The RMSE has the advantage in that it retains the unit of the forecast variable

Table 2. Combinations with/without data assimilation by additional datasets and NCEP/GFS global data for numerical weather predictions. The symbols in the model run of gfs, drp, cg and gps are defined in section 2.1. The others are the combinations of these four datasets.

\begin{tabular}{|c|c|c|c|c|c|}
\hline $\begin{array}{c}\text { Data } \\
\text { model run }\end{array}$ & $\begin{array}{l}\text { NCEP/GFS } \\
\text { global analysis }\end{array}$ & $\begin{array}{c}\text { Dropsonde } \\
\text { observations }\end{array}$ & $\begin{array}{l}\text { CIGU radar } \\
\text { radial velocity }\end{array}$ & $\begin{array}{l}\text { QuikSCAT } \\
\text { ocean winds }\end{array}$ & $\begin{array}{c}\text { FORMOSAT \#3/ } \\
\text { COSMIC } \\
\text { observations }\end{array}$ \\
\hline gfs & V & & & & \\
\hline drp & V & V & & & \\
\hline $\mathrm{cg}$ & V & & V & & \\
\hline qk & V & & & V & \\
\hline gps & V & & & & V \\
\hline cgdrp & V & V & V & & \\
\hline cggps & V & & V & & V \\
\hline drpgps & V & V & & & V \\
\hline qkdrp & V & V & & V & \\
\hline qkgps & V & & & V & V \\
\hline cgdrpgps & V & V & V & & V \\
\hline qkcgdrp & V & V & V & V & \\
\hline qkcggps & V & & V & V & V \\
\hline qkdrpgps & V & V & & V & V \\
\hline qkcgdrpgps & V & V & V & V & V \\
\hline
\end{tabular}


and is more easily interpretable as a typical error magnitude. The quantitative precipitation forecasts with low (or high) errors are more likely to have a better (or poorer) performance (Wilks 2006).

\section{IDENTIFICATION OF A MEI-YU FRONTAL BOUNDARY}

Through the incorporation of additional observations collected during 2008 SoWMEX/TiMREX with NCEP/ GFS global data by WRF 3D-Var system, the wind field and the associated kinematical fields (horizontal vorticity and divergence) are adjusted in the initial conditions of numerical model while the individual impact of additional data assimilation on the identification of the Mei-yu frontal boundary is revealed.
For the assimilation of dropsonde data (Fig. 6) at 0000 UTC on 4 June 2008, a Mei-yu frontal boundary passed through the southern tip of Taiwan and extended westward to the north of SCS, which is clearly identified with a significant wind shift at 950-hPa level (Fig. 6a). The location of the Mei-yu frontal boundary is more consistent with the analysis of surface front by the CWB of Taiwan as compared with the NCEP global forecasting system (GFS) (Fig. 6b). Meanwhile, the wind field at the 950-hPa level with the dropsonde data assimilated reveals the northwesterlies instead of the southwesterlies over the Taiwan Strait and the southerly winds strengthen over the Bashi Channel. In addition, the cyclonic vorticity (Fig. 6c) increases and has a maximum increment $\left(>3 \times 10^{-5} \mathrm{~s}^{-1}\right)$ over the north of SCS for the dropsonde assimilated compared with the NCEP/GFS data, while the low-level convergence (Fig. 6d)
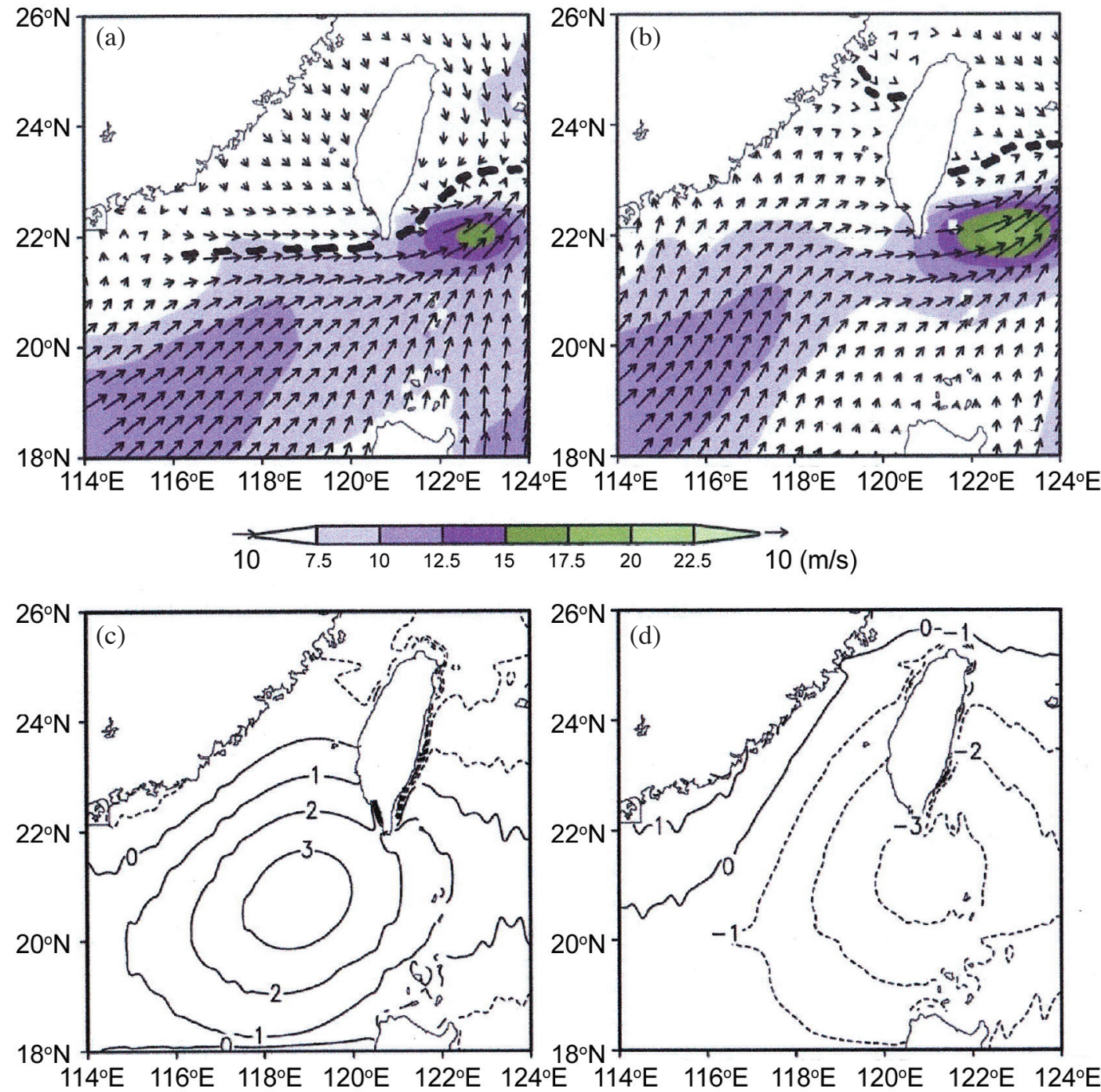

Fig. 6. (a) $950-\mathrm{hPa}$ wind field with the dropsonde (drp) data assimilation at 0000 UTC on 4 June 2008, (b) same as (a) but for NCEP/GFS (gfs) run, (c) difference in horizontal vorticity at $1 \times 10^{-5} \mathrm{~s}^{-1}$ intervals between drp and gfs run, and (d) difference in horizontal divergence at $1 \times 10^{-5} \mathrm{~s}^{-1}$ intervals between drp and gfs run. In (a) and (b), the dashed line represents the Mei-yu frontal boundary and wind speed (shaded) with $2.5 \mathrm{~m} \mathrm{~s}^{-1}$ intervals. 
also increase over the nearby ocean of Taiwan and a maximum difference $\left(>3 \times 10^{-5} \mathrm{~s}^{-1}\right)$ occurs near the southern tip of Taiwan over Bashi Channel. Therefore, the kinematical adjustment with the assimilation of the dropsondes reveals a favorable environmental condition for the formation of the rain-producing system along the Mei-yu frontal zone.

Through the assimilation of radar radial velocity (Fig. 7) in the model initial condition, the Mei-yu frontal boundary is split into east and west parts similar to the NCEP/GFS global analysis, but different from the CWB analysis. The west part of the surface front with radar radial velocity assimilated (Fig. 7a) moves southward faster than that shown by the NCEP-GFS global analysis (Fig. 7b), but slower than that analyzed by the CWB (Fig. 2a) and dropsonde data assimilated (Fig. 6a). The kinematical field (Figs. 7c and d) shows that the low-level cyclonic vortic- ity and the horizontal convergence increase over the nearby ocean of Taiwan. The southwesterly winds over the north of SCS are significantly strengthened. In contrast to the incorporation of dropsonde data and radar radial velocity, the assimilation of QuikSCAT ocean surface winds (Fig. 8) reveal that southwesterly winds prevail in the analyzed domain and the Mei-yu frontal boundary suddenly disappears (Fig. 8a). At the 950-hPa level, the cyclonic vorticity (Fig. 8c) also increases over the north of SCS with the maximum increment near the coast of southern China, but the horizontal divergence (Fig. 8d) increases over the nearby ocean of Taiwan. This will be probably unfavorable for the development of the rain-producing system along the Meiyu frontal zone over the north of SCS. For the retrieved atmospheric profiles from the assimilated FORMOSAT-3/ COSMIC observations (not shown), the impact on the ki-
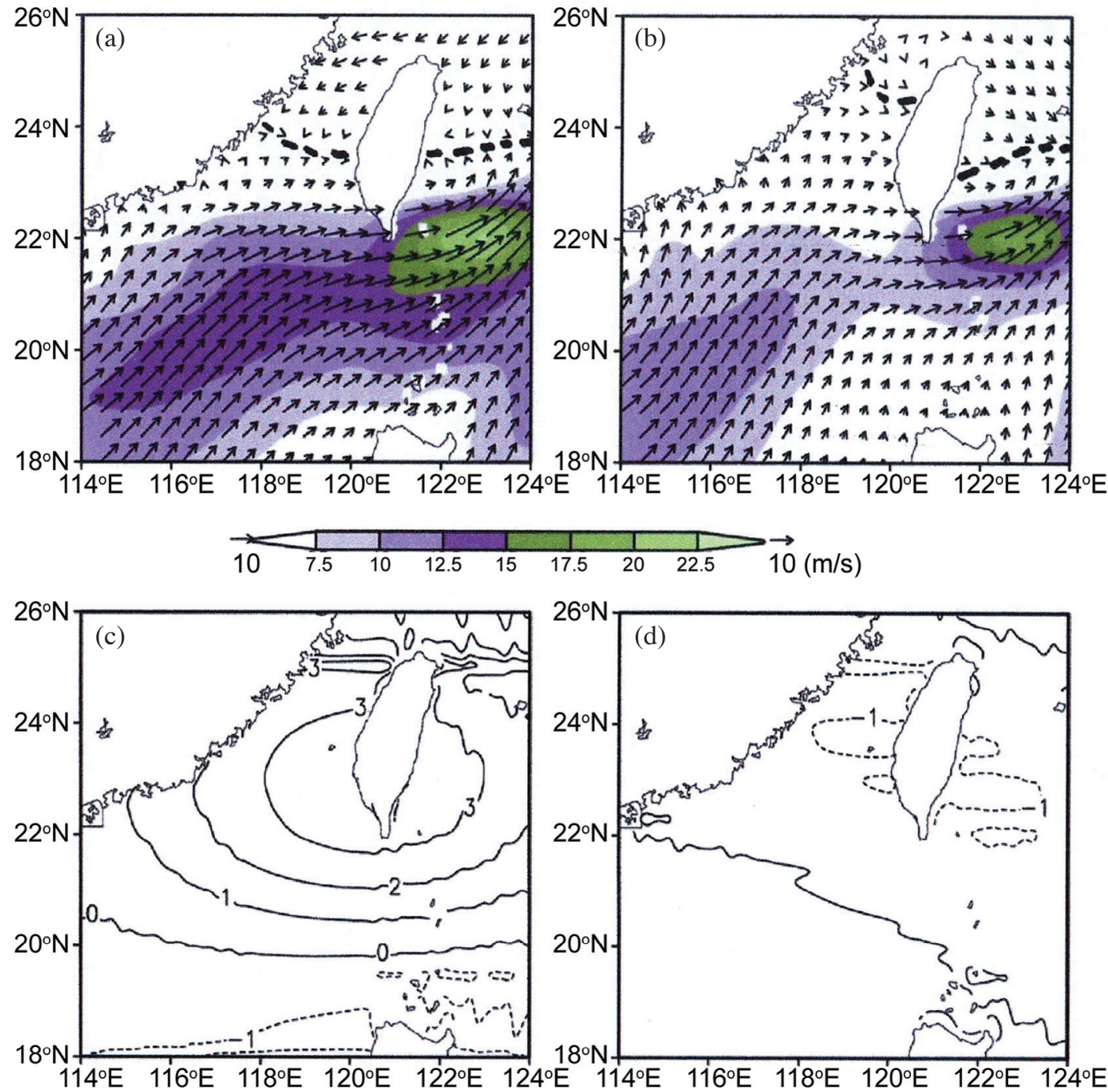

Fig. 7. (a) 950-hPa wind field with the Cigu radar radial velocity (cg) assimilation at 0000 UTC on 4 June 2008, (b) same as (a) but for NCEP/GFS (gfs) run, (c) difference in horizontal vorticity at $1 \times 10^{-5} \mathrm{~s}^{-1}$ intervals between cg and gfs run, and (d) difference in horizontal divergence at $1 \times 10^{-5}$ $\mathrm{s}^{-1}$ intervals between cg and gfs run In (a) and (b), the dashed line represents the Mei-yu frontal boundary and wind speed (shaded) with $2.5 \mathrm{~m} \mathrm{~s}^{-1}$ intervals. 

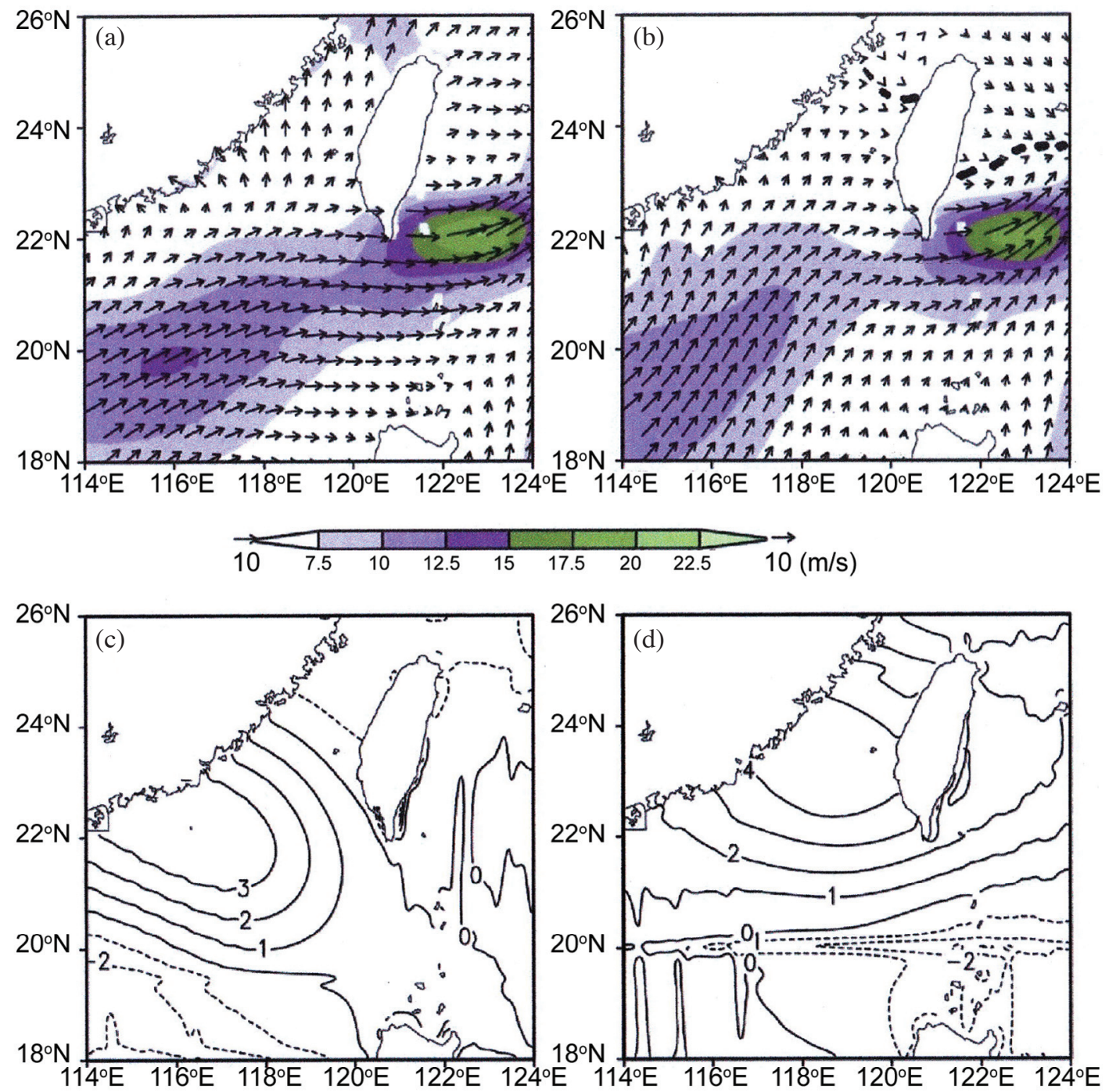

Fig. 8. (a) 950-hPa wind field with the QuikSCAT ocean surface winds (qk) assimilation at 0000 UTC on 4 June 2008, (b) same as (a) but for NCEP/ GFS (gfs) run, (c) difference in horizontal vorticity at $1 \times 10^{-5} \mathrm{~s}^{-1}$ intervals between qk and gfs run, and (d) Difference in horizontal divergence at $1 \times 10^{-5} \mathrm{~s}^{-1}$ intervals between qk and gfs run. In (a) and (b), the dashed line represents the Mei-yu frontal boundary and wind speed (shaded) with $2.5 \mathrm{~m} \mathrm{~s}^{-1}$ intervals.

nematical field is slightly adjusted in the model initial conditions. In this study, the assimilation of radar radial velocity (cg), QuikSCAT ocean surface winds (qk), the FORMOSAT-3/COSMIC observations (gps) and the associated combinations (cggps, qkgps, qkcggps) cannot identify the Mei-yu frontal boundary very well over the open ocean in the model initial conditions, as compared with the CWB surface weather analysis and the assimilated dropsonde observations.

Through the regional mean $\left(118-121^{\circ} \mathrm{E} ; 20-22^{\circ} \mathrm{N}\right)$ in the difference of the kinematical field between additional assimilated datasets and NCEP/GFS global data in the model initial conditions, the 950-hPa horizontal cyclonic vorticity (Fig. 9a) is increased along the Mei-yu frontal zone by data assimilation, except for FORMOSAT-3/COSMIC observations. For the 950-hPa horizontal divergence (Fig. 9b), the data assimilation with dropsondes and associated combinations reveals significant increase of horizontal convergence over the north of the SCS and Bashi Channel. But for the QuikSCAT ocean surface winds and FORMOSAT-3/COSMIC observations and the associated combinations (qkgps and qkcggps), the horizontal divergence increases there, which may be not favorable for the development of rainproducing systems along the Mei-yu frontal zone.

\section{PREDICTION OF A MEI-YU FRONTAL CYCLONE}

As analyzed by the CWB of Taiwan during $4-5$ June 2008, a Mei-yu frontal cyclone (Fig. 2) accompanied a developing convection (Fig. 3) which was revealed over the north of the SCS, which is related to the production of torrential rainfall over southern Taiwan on 5 June 2008. The 
(a)

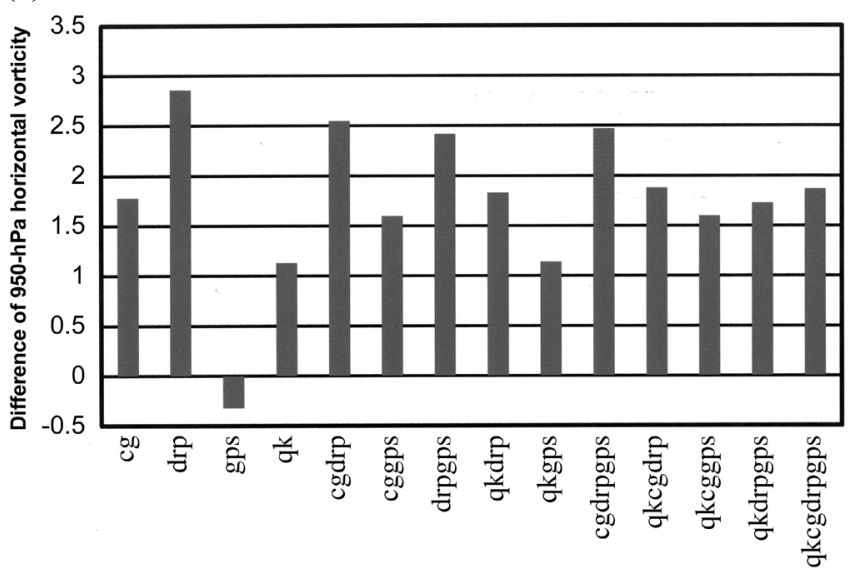

(b)

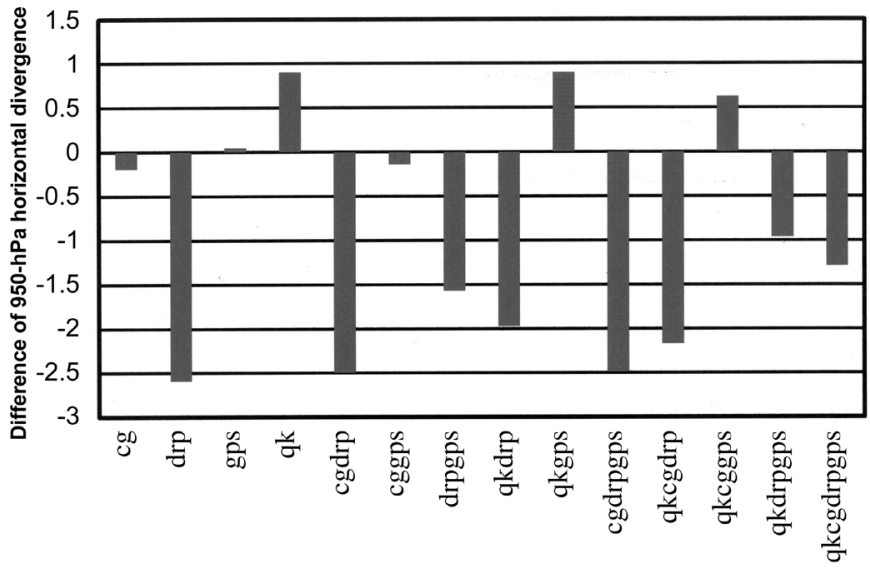

Fig. 9. (a) Regional mean $\left(118-121^{\circ} \mathrm{E} ; 20-22^{\circ} \mathrm{N}\right)$ of the $950-\mathrm{hPa}$ horizontal vorticity $\left(\times 10^{-5} \mathrm{~s}^{-1}\right)$ in the differnce between additional datasets and the NCEP/GFS run at 0000 UTC on 4 June 2008, respectively. (b) The same as (a) but for the horizontal divergence $\left(\times 10^{-5} \mathrm{~s}^{-1}\right)$.

formation and development of this MFC along the Meiyu frontal zone over the open ocean can be predicted using the additional observations [Cigu radar radial velocity (cg), dropsondes from aircraft observations (drp), FORMOSAT-3/COSMIC retrieved atmospheric profiles (gps), and QuikSCAT ocean surface winds (qk)] (Fig. 5). Note that the prediction of torrential rainfall on 5 June can be significantly improved by the data assimilation using the cgdrp data as will be shown in section 6 . Thus, the prediction of a MFC through the cgdrp combinations is presented (Figs. 10, 11 and 12) and compared with the prediction by NCEP/GFS global data as well as four additional data (qkcgdrpgps) combinations. Also, the effect of latent heat release on the development of the Mei-yu frontal cyclone is discussed.

At 1200 UTC on 4 June, the 12-hr predicted sea level pressure field reveals that a low-pressure system with the cyclonic circulation formed over the north of the SCS (Figs. 10a, b and c) using the GFS data, and the data assimilation with the cgdrp and qkcgdrpgps combinations, which is 12-hr earlier reproduced the MFC by numerical modeling than that in the surface map analyzed by the CWB of Taiwan. Significant rainfall was reproduced over the north of the SCS near the center and the east of the low pressure in the presence of latent heat release (Figs. 10a, b, c and d).

At 0000 UTC on 5 June, the 24-hr prediction using the cgdrp and qkcgdrpgps combinations (Figs. 11b and c) reveals that the MFC develops and strengthens over the north of SCS, compared with the NCEP/GFS prediction (Fig. 11a). The predicted 3-hr accumulated rainfall using the cgdrp assimilation reproduces the weak rainfall inland over southern Taiwan and significant rainfall over the nearby ocean southwest of Taiwan (Fig. 11b) which is more consistent with satellite imagery (Fig. 3c) and radar reflectivity revealed by Lai et al. (2011; Fig. 10) as compared with the prediction by the GFS (Fig. 11a) and the others (Figs. 11c and d). Meanwhile, low-level winds over southern Taiwan (south of $23^{\circ} \mathrm{N}$ ) turn to southerly-to-southeasterly winds predicted by the cgdrp and qkcgdrpgps combinations (Figs. 11b and c), more consistent with the observations (Fig. 4). But lowlevel winds predicted by NCEP/GFS are more southwesterly (Fig. 11a). Recall that surface winds over southern Taiwan are southerly-to-southeasterly in the time slot of 0000 - 0900 UTC on 5 June with significant rainfall over southern Taiwan. For the prediction in the absence of the latent heat release (Fig. 11d), the MFC does not develop over the north of the SCS and significant rainfall is not reproduced over the open ocean. As analyzed by Chen et al. (2003), the Mei-yu frontal zone has provided low-level convergence and helped organize the convection, while latent heating by the convections has further enhanced the Mei-yu frontal system. Here, the incorporation of dropsonde observations and the associated combinations can increase the low-level convergence (Fig. 9b) along the frontal zone in the model initial conditions. It provides a favorable condition for the formation of a MFC in the western flank of the Mei-yu frontal zone over the north of SCS. And the effect of the latent heating plays an important role in development and maintenance of a MFC over the open ocean before it approaches the western coast of southern Taiwan. As analyzed by a previous study (Yeh and Chen 2004), latent heating has been suggested to be responsible for the development of a surface frontal cyclone in the western flank of a Mei-yu frontal system over the nearby ocean in the east of Taiwan.

At 1200 UTC on 5 June, the MFC predicted by the cgdrp (Fig. 12b) almost landfalls to the western coast of southern Taiwan, while significant rainfall is reproduced in the eastern area of southern Taiwan (Fig. 1) consistent with the satellite imagery (Fig. 3d). Some rainfall is also reproduced over the nearby ocean of southern Taiwan. For the predictions using NCEP/GFS data (gfs run) and the qkcgdrpgps combination (Figs. 12a and c), the low pressure center was still located offshore, southwest of Taiwan. The 
predicted 3-hr accumulated rainfall by NCEP/GFS (Fig. 12a) reproduced the significant rainfall over land distributed slightly northward and the qkcgdrpgps run (Fig. 12c) reproduced more rainfall over the southeastern Taiwan. Here, using a cgdrp combination can clearly improve the prediction associated with the development of a MFC over the north of the SCS. Also low-level southerly and southeasterly winds over southern Taiwan are captured and interact with the island obstacle.

In addition, the track of the predicted center of a MFC using additional data assimilation is revealed in Fig. 13. In comparison with the track of MCV center identified by visible satellite imageries (Chi and Huang 2011), the predicted track by the cgdrp run (Fig. 13a) shows that the MFC moves southward and then eastward toward western coast of southern Taiwan during 0000 - 0900 UTC, which is more consistent with the observation. Thus, the cgdrp run can significantly improve the daily rainfall prediction over southern Taiwan on 5 June 2008, which will be presented in the section 5. For the qkcgdrpgps run (Fig. 13a), the track of the MFC is located to the north of the cgdrp run and the observations.

For individual datasets, the predicted MFC center by the dropsonde data assimilated (Fig. 13a) moves eastward and reaches the coast of southern Taiwan around 0900 UTC, which is a little northward as compared with the observation.
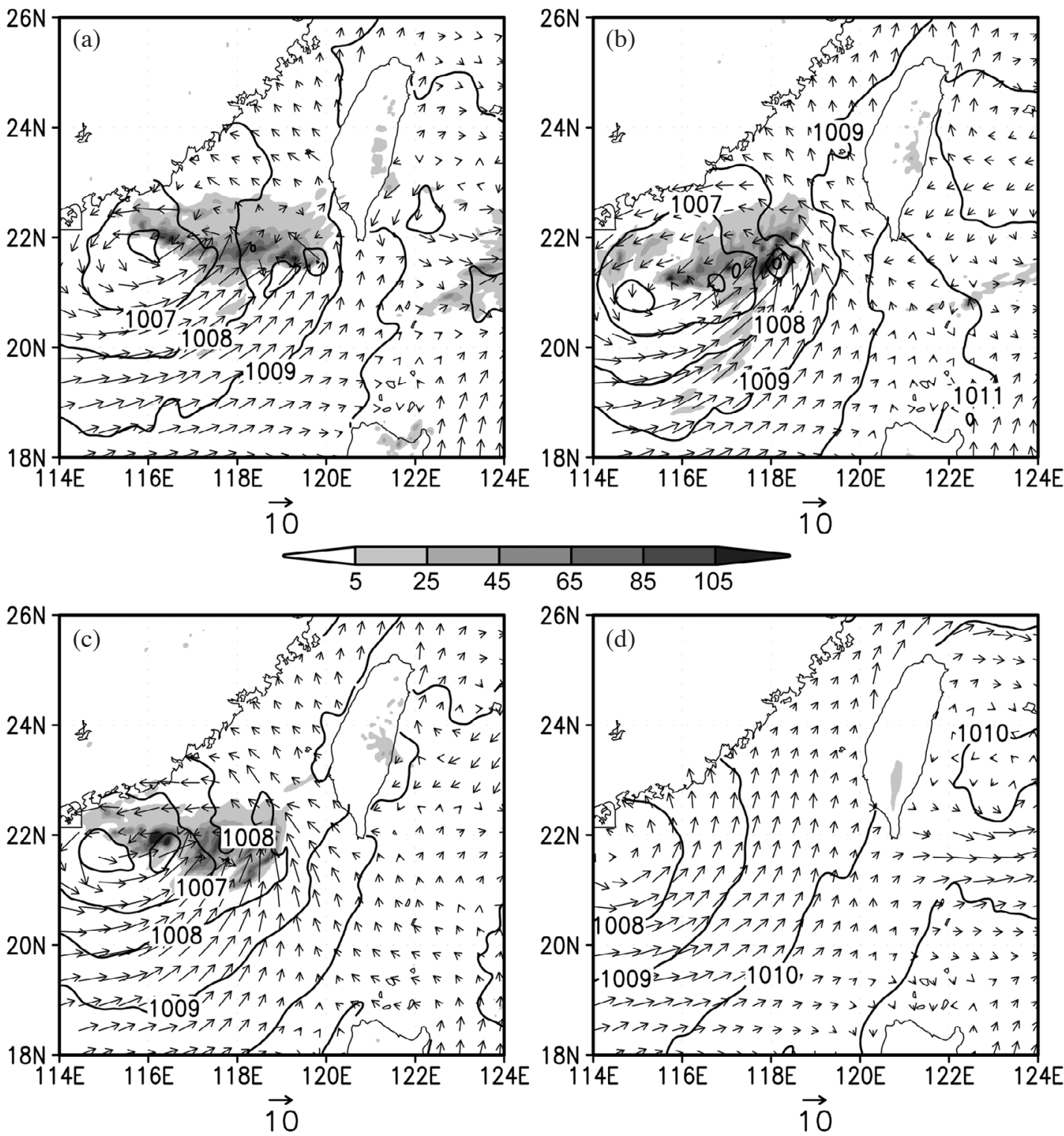

Fig. 10. 12-hr prediction (valid at 1200 UTC on 4 June 2008) in the 950-hPa wind vector, sea-level pressure (solid) and 3-hr accumulated rainfall (shaded), (a) using NCEP/GFS (gfs) global data, (b) with the data assimilation by the dropsondes (drp) and radar radial velocity (cg), (c) with the data assimilation by the dropsondes (drp), radar radial velocity (cg), QuikSCAT winds (qk) and Formosa \#3/COSMIC atmospheric profiles (gps), and (d) without latent heat release. The sea-level pressure with 1-hPa intervals and the rainfall with 20-mm intervals. 

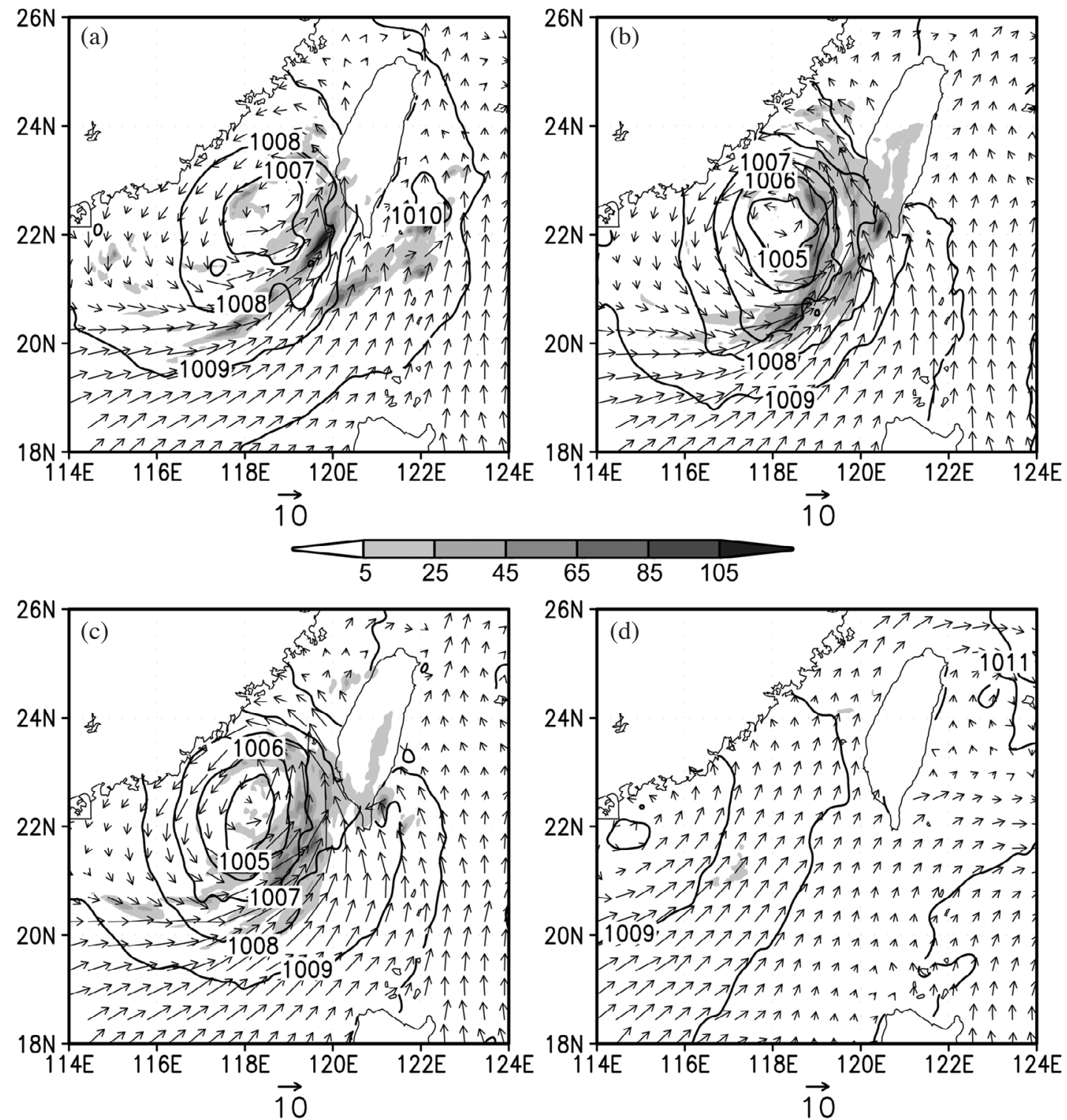

Fig. 11. 24-hr prediction (valid at 0000 UTC on 5 June 2008) in the 950-hPa wind vector, sea-level pressure (solid) and 3-hr accumulated rainfall (shaded), (a) using NCEP/GFS (gfs) global data, (b) with the data assimilation by the dropsondes (drp) and radar radial velocity (cg), (c) with the data assimilation by the dropsondes (drp), radar radial velocity (cg), QuikSCAT winds (qk) and Formosa \#3/COSMICatmospheric profiles (gps), and (d) without latent heat release. The sea-level pressure with 1-hPa intervals and the rainfall with 20-mm intervals.

For the gfs run (Fig. 13a), the predicted track of the MFC, similar to the analysis by Lai et al. (2011), moves northeastward and approaches the southwestern coast around 0600 UTC on 5 June, which is far north of the observation. In addition, the predicted MFC during daytime hours by the qk, cg, and gps run (Fig. 13b) also moves toward the southwestern coast of Taiwan. Meanwhile, the associated combinations of the cggps, qkgps and qkcggps run also cannot predict the track well (Fig. 13c) as compared with the observations (Fig. 13a). Recall that the cg, qk and gps run can not improve the identification of a Mei-yu frontal boundary over the open ocean. And the qk and gps run has reduced the horizontal convergence along the Mei-yu frontal zone in the model initial conditions. The difference in the predicted track of the MFC may affect the prediction of the daily rainfall distribution over southern Taiwan.

\section{IMPACT ON DAILY RAINFALL PREDICTION}

A MFC developed along the western flank of the Meiyu frontal system over the north of the SCS during 4 - 5 June 2008 and produced torrential rainfall ( $\left.\geqq 200 \mathrm{~mm} \mathrm{day}^{-1}\right)$ over southern Taiwan (south of $23^{\circ} \mathrm{N}$ ). With the incorporation of additional observations during SoWMEX/TiMREX, the daily rainfall predictions with/without data assimilation using 15 combinations (Table 2) are conducted. 

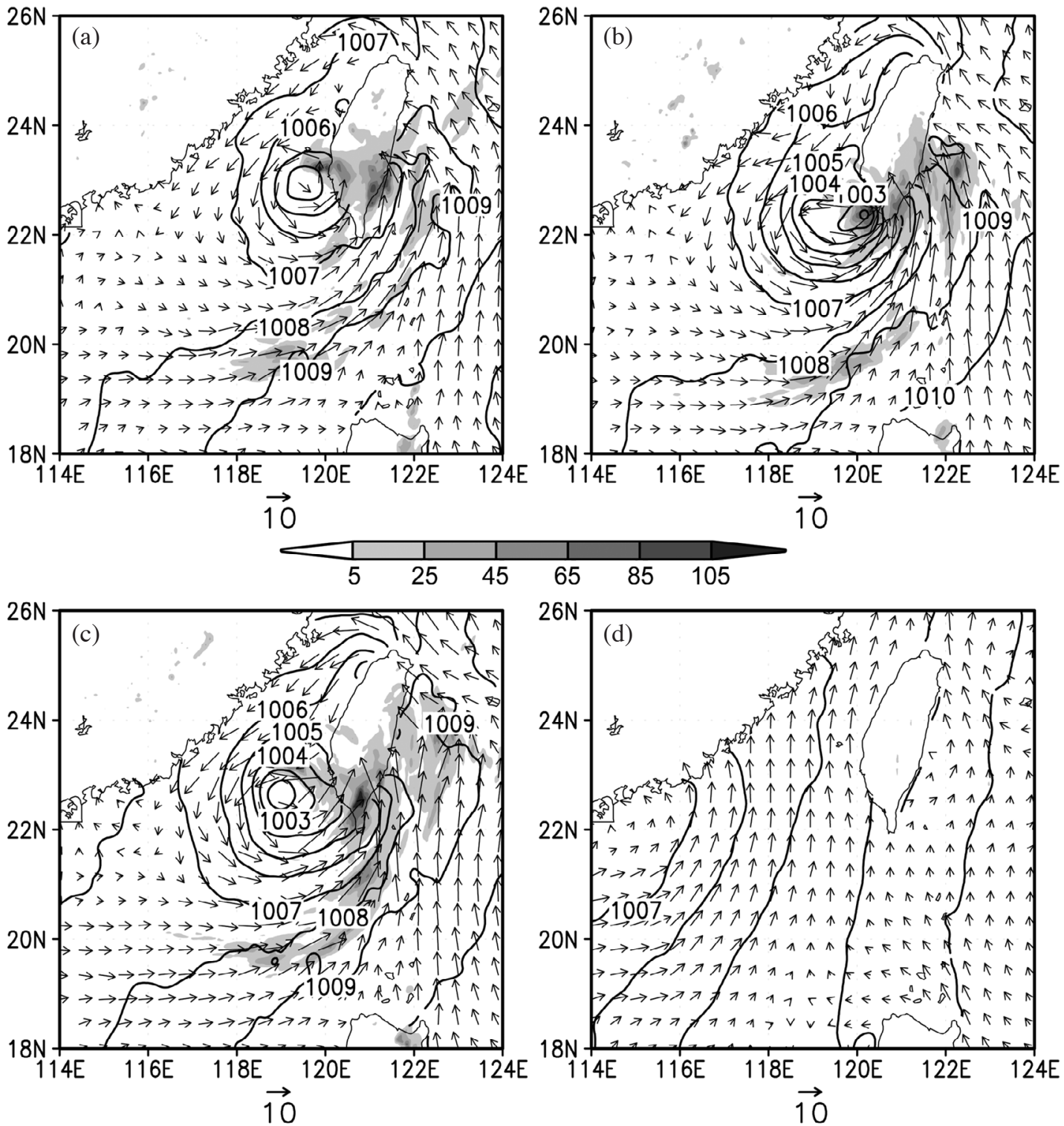

Fig. 12. 36-hr prediction (valid at 1200 UTC on 5 June 2008) in the 950-hPa wind vector, sea-level pressure (solid) and 3-hr accumulated rainfall (shaded), (a) using NCEP/GFS (gfs) global data, (b) with the data assimilation by the dropsondes (drp) and radar radial velocity (cg), (c) with the data assimilation by the dropsondes (drp), radar radial velocity (cg), QuikSCAT winds (qk) and Formosa \#3/COSMIC atmospheric profiles (gps), and (d) without latent heat release. The sea-level pressure with 1-hPa intervals and the rainfall with 20-mm intervals.

For the statistical verification of daily rainfall prediction on 5 June, the RMSE (Fig. 14) shows that data assimilation by the dropsondes (drp) only has better performance compared with the predictions by gfs, cg, qk, and gps respectively. Here, the assimilated dropsondes from aircraft observations can improve the daily rainfall prediction over southern Taiwan (south of $23^{\circ} \mathrm{N}$ ). Also, the daily rainfall prediction (Figs. 15a, b, c, and d) using the dropsonde only (Fig. 15a) shows that the torrential rainfall ( $\left.\geqq 200 \mathrm{~mm} \mathrm{day}^{-1}\right)$ is distributed in the western and eastern coastal regions of southern Taiwan, which is more consistent with the observed rainfall distribution (Fig. 1). Meanwhile, the daily rainfall prediction by gfs run (Fig. 14e) reproduces the precipitation maximum on the southwest side on Taiwan too far north. It seems that the rainfall prediction through $\mathrm{cg}$, qk, and gps alone does not improve at all (Figs. 15b, c, and d). Note that the track of the MFC predicted by cg, qk and gps run moves toward the southwestern coast, but not toward the southern coast as revealed by the observations (Fig. 13b).

For the combinations of four additional data assimilated, the combinations with the dropsondes (Fig. 14) can improve the daily rainfall prediction over southern Taiwan, except for qkdrpgps and qkcgdrpgps. The improvement in daily rainfall prediction by the dropsonde combinations (cgdrp, qkdrp, drpgps, cgdrpgps, and qkcgdrp) may relate to the increase the low-level horizontal convergence (Fig. 9b) 

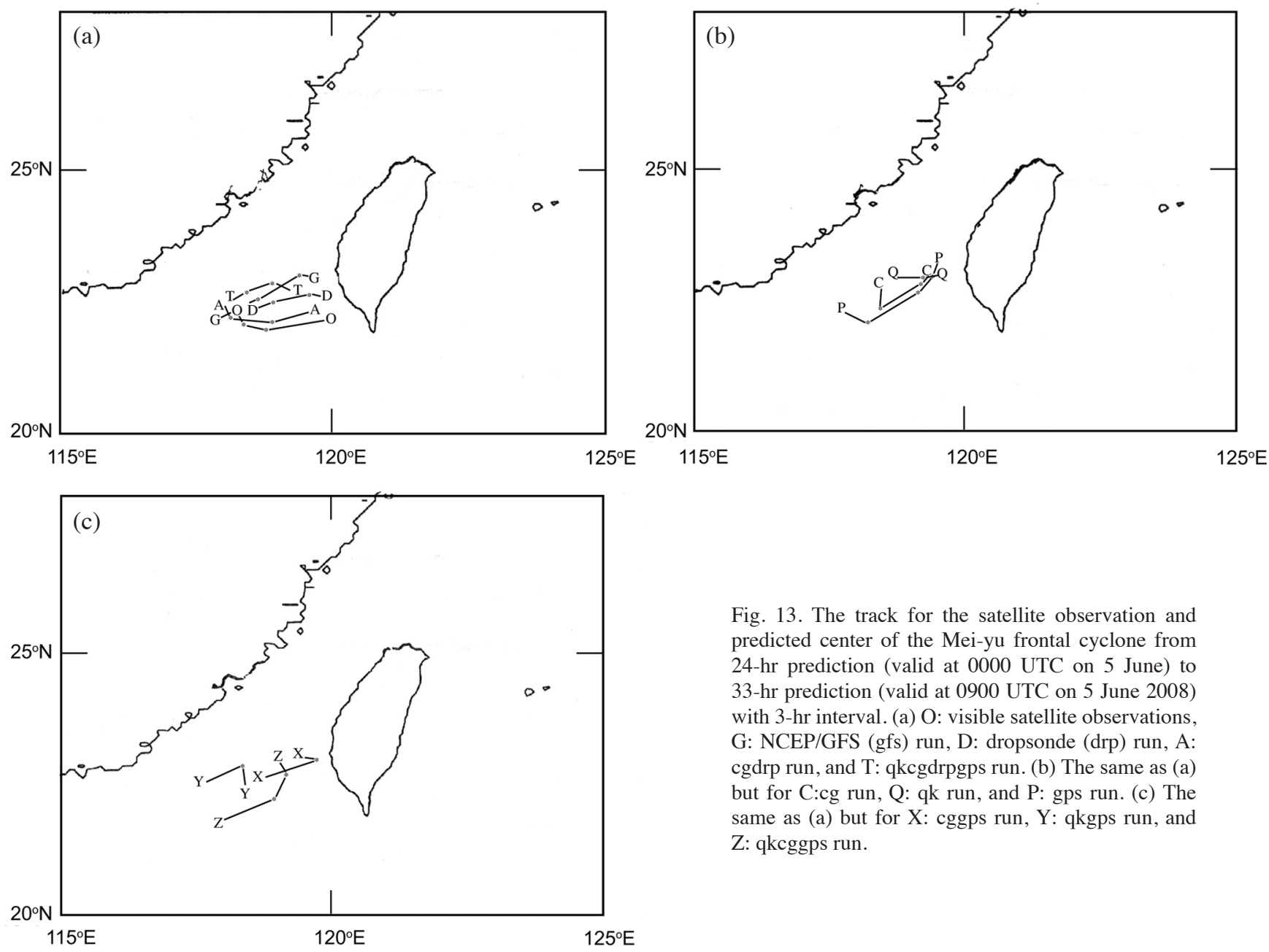

Fig. 13. The track for the satellite observation and predicted center of the Mei-yu frontal cyclone from 24-hr prediction (valid at 0000 UTC on 5 June) to 33 -hr prediction (valid at 0900 UTC on 5 June 2008) with 3-hr interval. (a) O: visible satellite observations, G: NCEP/GFS (gfs) run, D: dropsonde (drp) run, A: cgdrp run, and T: qkegdrpgps run. (b) The same as (a) but for C:cg run, Q: qk run, and P: gps run. (c) The same as (a) but for X: cggps run, Y: qkgps run, and $\mathrm{Z}$ : qkcggps run.

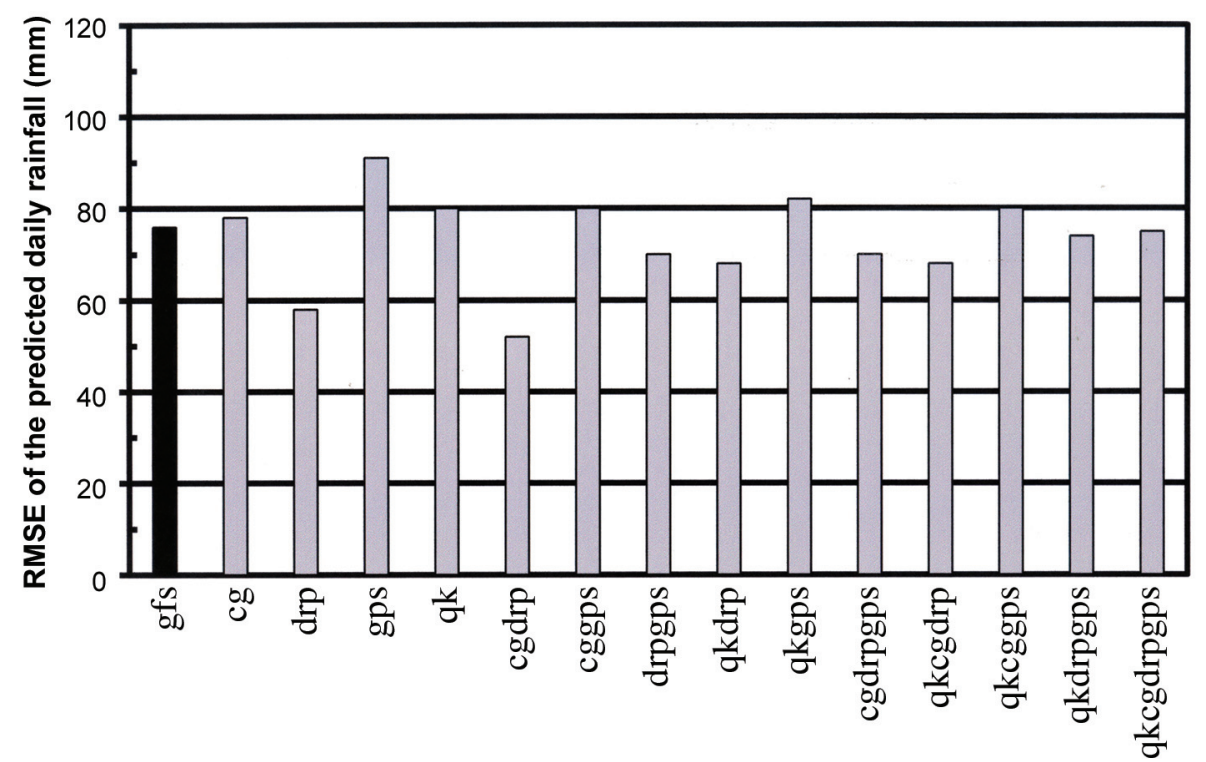

Fig. 14. Root-mean squared error (RMSE) for the predicted daily rainfall over southern Taiwan on 5 June 2008 from 16-hr prediction (valid at 1600 UTC on 4 June) to 40-hr prediction (valid at 1600 UTC on 5 June ), using NCEP/GFS global data (gfs), and with data assimilation by the dropsondes (drp), radar radial velocity (cg). QuikSCAT winds (qk) and Formosa \#3/COSMIC atmospheric profiles (gps) as well as the combinations of these additional data. 
(a)

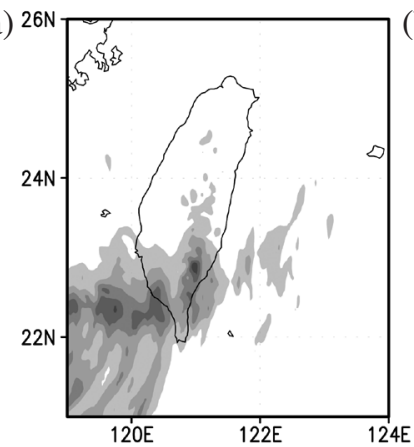

(b)

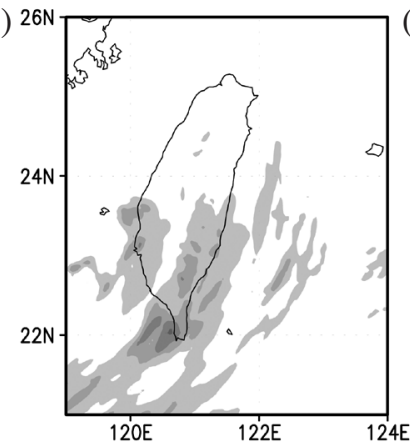

(c) 2

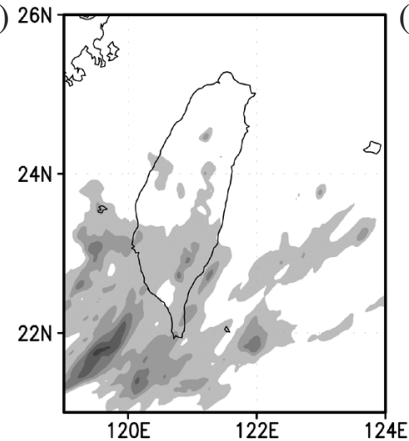

(d) 2 (

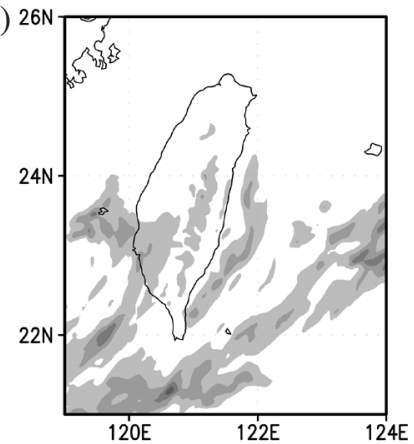

(e)

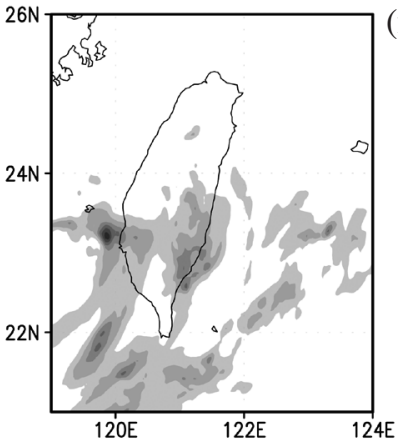

(f)

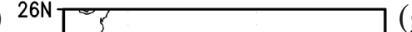

(g)

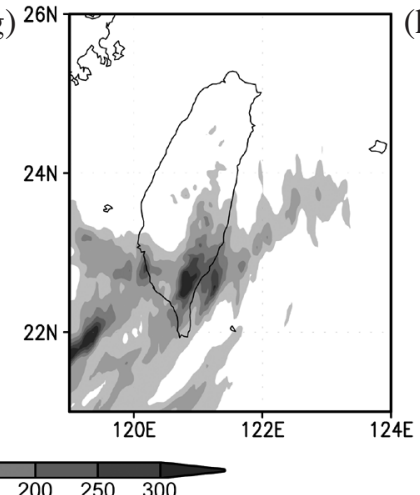

(h)

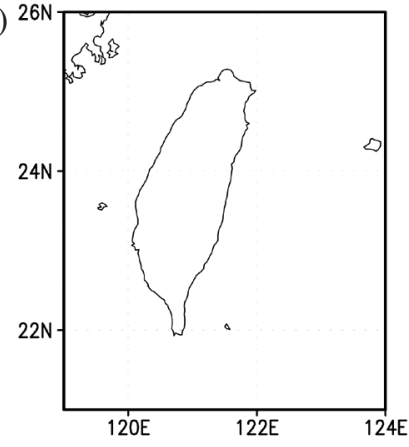

Fig. 15. Predicted daily rainfall (shaded) over Taiwan on 5 June 2008 from 16-hr prediction (valid at 1600 UTC on 4 June) to 40 -hr prediction (valid at 1600 UTC on 5 June ), using (a) dropsondes (drp), (b) radar radial velocity (cg), (c) QuikSCAT winds (qk), (d) FORMOSA-3/COSMIC atmospheric profiles (gps), (e) NCEP/GFS global data (gfs), (f) cgdrp data, (g) qkcgdrpgps data, and (h) without latent heat release. In (a), (b), (c), (d), (f), and (g), additional data assimilated with NCEP/GFS global data. The rainfall with 50-mm intervals.

along Mei-yu frontal zone over the north of SCS and Bashi Channel in the initial condition of numerical model, which is favorable for the formation of the rain-producing system along the Mei-yu frontal zone. Particularly, the prediction with data assimilation using the cgdrp can obviously capture the development and movement of a MFC with the best track (Fig. 13a) over the open ocean during 4 - 5 June (Figs. 10, 11, 12 and 13). The MFC moves toward southern Taiwan and serves as the dominant weather system to produce torrential rainfall there. Thus, the cgdrp run presents an optimal daily rainfall prediction over southern Taiwan (Figs. 14 and 15f) compared with the gfs run (Fig. 15e) and the other combinations (Fig. 15), because the low-level southerly and southeasterly winds are predicted, which may interact with island obstacles over coastal regions of southern Taiwan as the MFC approaches (Figs. 11b and 12b). But for the qkcgdrpgps with four additional data assimilated, the predicted daily rainfall (Figs. 14 and $15 \mathrm{~g}$ ) do not apparently improve the daily rainfall prediction with more daily rainfall in the east and less daily rainfall in the west of southern Taiwan. The predicted track of the MFC by the qkcgdrpgps (Fig. 13a) may affect rainfall prediction. In addition, the combinations of cg, qk and gps assimilation (cggps, qkgps, and qkcggps) do not improve the daily rainfall prediction, which may be related to the model initial conditions and the predicted track of the MFC (Fig. 13c)

Furthermore, the regional mean $\left(120.4-120.6^{\circ} \mathrm{E}\right.$; $22.5-22.7^{\circ} \mathrm{N}$ ) of predicted $925-\mathrm{hPa}$ horizontal wind field and relative humidity $(\mathrm{RH})$ by the NCEP/GFS run and the combinations of additional datasets are statistically evaluated by the RMSE (Fig. 16). Here, the 46750 sounding data (Fig. 4) over southern Taiwan from 1800 UTC on 4 June to $1800 \mathrm{UTC}$ on 5 June are used. For the gfs run, the errors in the predicted horizontal wind field (Figs. 16a and b) are associated with the southwesterly wind instead of the southeasterlies in the observations during the 0000 - 0900 UTC on 5 June. The RMSE in the RH predicted by the gfs run (Fig. 16c) is related to the moisture content reproduced higher than the observations.

For individual additional data assimilations, the drp run improves the prediction in the $925-\mathrm{hPa}$ horizontal wind field with relatively smaller RMSE, compared with the $\mathrm{cg}$, gps, and qk run. Note that the track of the MFC is better predicted by the drp run than that by the $\mathrm{cg}$, gps, and $\mathrm{qk}$ run. The errors in the wind field using drp are related to the stronger southeasterly wind. But for the $\mathrm{cg}$, $\mathrm{qk}$ and gps run, the low-level winds change to south-westerlies. The low-level winds different from the observations may affect the prediction in the daily rainfall distribution over southern Taiwan. 
(a)

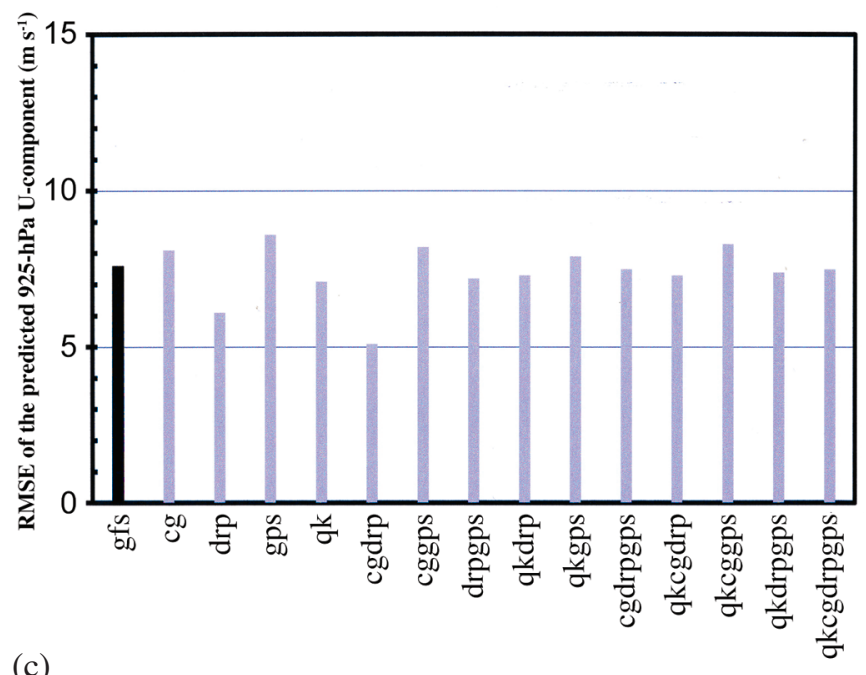

(c)

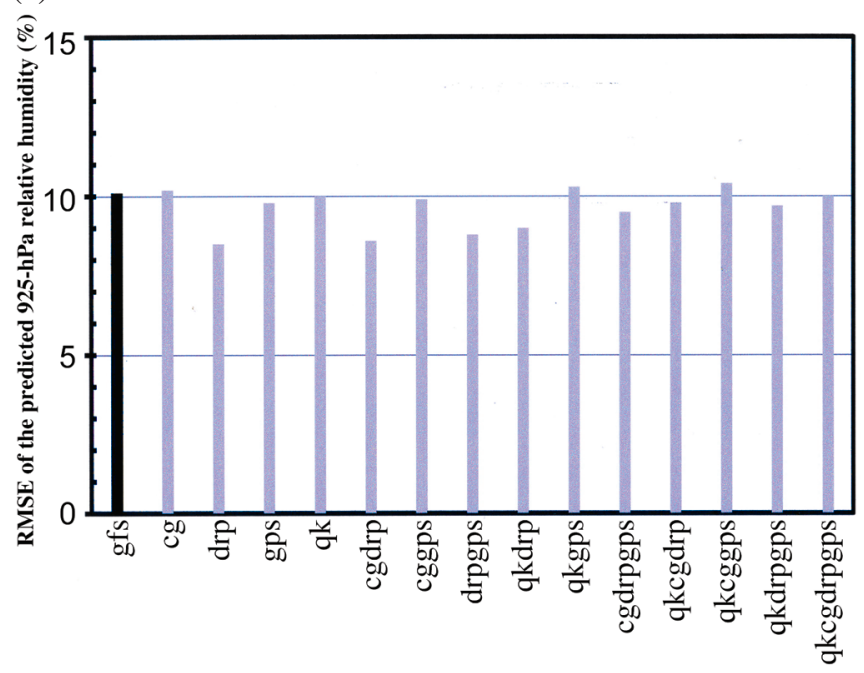

(b)

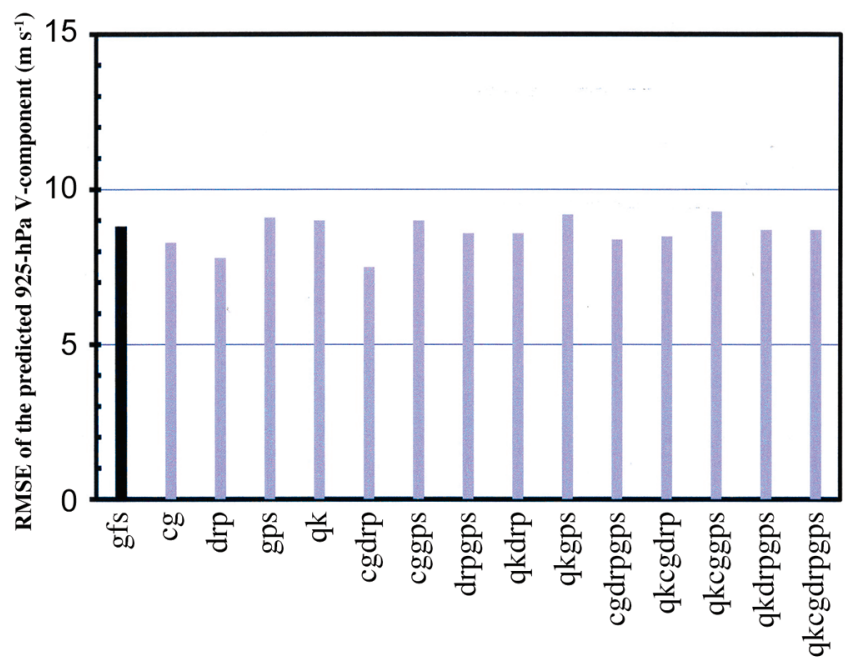

Fig. 16. Root-mean squared error (RMSE) (a) for the predicted 925-hPa U-component of horizontal wind $\left(\mathrm{m} \mathrm{s}^{-1}\right)$ from the sounding 46750 over southern Taiwan from 18-hr prediction (valid at 1800 UTC on 4 June) to 42-hr prediction (valid at 1800 UTC on 5 June 2008), (b) the same as (a) but for the V-component of horizontal wind $\left(\mathrm{m} \mathrm{s}^{-1}\right)$, and (c) the same as (a) but for the relative humidity (\%).
For the combinations of additional datasets, the cgdrp run has improved the predictions in the low-level wind field and the RH (Fig. 16). Note that the cgdrp run can obviously improve the prediction in the daily torrential rainfall distribution (Figs. 14 and 15f) over southern Taiwan and the track of a MFC over ocean (Fig. 13). For the other dropsonde combinations (drpgps, qkdrp, cgdrpgps, qkcgdrp), the associated predictions in the $925-\mathrm{hPa}$ horizontal wind field and RH (Fig. 16) are slightly improved as compared with the gfs run. Meanwhile, the errors in the 925-hPa horizontal wind field are related to the stronger southeasterly winds predicted. However, the improvement in prediction of lowlevel wind and RH by the qkdrpgps; and the qkcgdrpgps becomes insignificant. For the cggps, qkgps and qkcggps run (Fig. 16) without combining with the dropsonde data, the 925-hPa winds turn to the southwesterlies and are different from the winds revealed by the 46750 soundings (Fig. 4). This is similar to the cg and gps run. The errors in the 925$\mathrm{hPa}$ wind field may affect the daily rainfall prediction.

\section{CONCLUSIONS}

During 2008 Taiwan Mei-yu season, a torrential rain event $\left(\geqq 200 \mathrm{~mm}\right.$ day $\left.^{-1}\right)$ on 5 June occurred over coastal regions of southern Taiwan (south of $23.0^{\circ} \mathrm{N}$ ) which is associated with an approaching MFC which developed over the north of the SCS along the Mei-yu frontal zone during 4 - 5 June, 2008. The atmospheric environment shows a nearneutral condition with the increase of moisture content during the rainfall period (0000 - 1200 UTC) on 5 June. And low-level winds significantly turn to southerly or southeasterly winds over southern Taiwan to interact with Island obstacle during the daytime hours (0000 - 0900 UTC). After the production of torrential rainfall, low-level winds change to a westerly wind and the atmosphere subsequently becomes drier over southern Taiwan.

Using additional dropsonde data assimilated through WRF 3D-Var system in the model initial condition at 0000 UTC on 4 June 2008, the location of a distorted Mei-yu 
frontal boundary passed through the southern tip of Taiwan and extended westward to the north of SCS, which is clearly identified with significant wind shift. The location of the Mei-yu frontal boundary is more consistent with the analysis of surface front from the CWB of Taiwan. Meanwhile, the cyclonic vorticity and horizontal convergence are increased over the north of SCS in low levels, which may provide a favorable environmental condition for the formation of the rain-producing system along the Mei-yu frontal zone. However, the cg, qk and gps assimilation as well as the associated combinations (cggps, qkgps and qkcggps) cannot well identify the Mei-yu frontal boundary over the open ocean. And the qkgps and qkcggps assimilated have reduced the horizontal convergence along the Mei-yu frontal zone in the model initial conditions, which is unfavorable for the development of rain systems there.

For the prediction of the MFC over the north of SCS, using the combination of dropsonde and radar radial velocity (cgdrp) datasets can clearly reproduce the development of a MFC with the best track over the open ocean. Also, the low-level southerly and southeasterly winds over southern Taiwan are predicted and interact with the island obstacle during the rainfall period on 5 June 2008. Thus, the cgdrp run can significantly improve the daily rainfall prediction over southern Taiwan on 5 June 2008 which is better than the daily rainfall prediction by the NCEP-GFS and the other additional data assimilation. In addition, latent heating plays an important role in the development and maintenance of a MFC along the Mei-yu frontal zone over the open ocean.

Furthermore, this is a successful case to reveal that the data assimilation using dropsonde data can improve the identification of the Mei-yu frontal boundary over the open ocean near southern Taiwan during the Mei-yu season. The results may apply in the counterpart cases in future.

Acknowledgements This work is supported by the National Science Council in Taiwan under the Grants NSC 98-2625-M-156-001, NSC 100-2625-M-052-001, and NSC 101-2625-M-156-001. Thanks to the 2008 SoWMEX/TiMREX and CWB of Taiwan for providing additional data and to NCAR MMM for providing the WRF 3D-Var system. And thanks to the NASA Ocean Vector Winds Science Team which sponsored and provided the QuikSCAT satellite-derived ocean surface winds through Remote Sensing System. Thanks also go to the anonymous reviewers for their valuable comments and suggestions.

\section{REFERENCES}

Barker, D. M., W. Huang, Y. R. Guo, A. J. Bourgeois, and Q. N. Xiao, 2004: A three-dimensional variational data assimilation system for MM5: Implementation and initial results. Mon. Weather Rev., 132, 897-914, doi: 10. 1175/1520-0493(2004)132<0897:ATVDAS>2.0.CO;

\section{2. [Link]}

Chen, C. S., 1991: A numerical study of a squall line over the Taiwan Strait during TAMEX IOP 2. Mon. Weather Rev., 119, 2677-2698, doi: 10.1175/1520-0493(19 91) $119<2677$ :ANSOAS>2.0.CO;2. [Link]

Chen, C. S. and Y. L. Chen, 2003: The rainfall characteristics of Taiwan. Mon. Weather Rev., 131, 1323-1341, doi: 10.1175/1520-0493(2003)131<1323:TRCOT>2.0. CO;2. [Link]

Chen, C. S., W. C. Chen, Y. L. Chen, P. L. Lin, and H. C. Lai, 2005: Investigation of orographic effects on two heavy rainfall events over southwestern Taiwan during the Mei-yu season. Atmos. Res., 73, 101-130, doi: 10. 1016/j.atmosres.2004.07.005. [Link]

Chen, C.S., Y.L.Chen, C. L.Liu, P.L.Lin, and W.C.Chen, 2007: Statistics of heavy rainfall occurrences in Taiwan. Weather Forecast., 22, 981-1002, doi: 10.1175/ WAF1033.1. [Link]

Chen, C. S., Y. L. Lin, W. C. Peng, and C. L. Liu, 2010: Investigation of a heavy rainfall event over southwestern Taiwan associated with a subsynoptic cyclone during the 2003 Mei-Yu season. Atmos. Res., 95, 235-254, doi: 10.1016/j.atmosres.2009.10.003. [Link]

Chen, F. and J. Dudhia, 2001: Coupling an advanced land surface - Hydrology model with the Penn State - NCAR MM5 modeling system. Part I: Model implementation and sensitivity. Mon. Weather Rev., 129, 569-585, doi: 10.1175/1520-0493(2001)129<0569:CAALSH > 2.0.C O;2. [Link]

Chen, G. T.-J., 1983: Observational aspects of the Mei-yu phenomenon in subtropical China. J. Meteorol. Soc. Jpn., 61, 306-312.

Chen, G. T.-J., 1992: Mesoscale features observed in the Taiwan Mei-yu season. J.Meteorol.Soc.Jpn., 70, 497516.

Chen, G. T.-J. and C. C. Yu, 1988: Study of low-level jet and extremely heavy rainfall over northern Taiwan in the Mei-yu season. Mon. Weather Rev., 116, 884-891, doi: 10.1175/1520-0493(1988)116<0884:SOLLJA>2.0. CO;2. [Link]

Chen, G. T.-J., C. C. Wang, and S. C.-S. Liu, 2003: Potential vorticity diagnostics of a Mei-yu front case. Mon. Weather Rev., 131, 2680-2696, doi: 10.1175/1520-04 93(2003)131<2680:PVDOAM>2 .0.CO;2. [Link]

Chen, X. A. and Y. L. Chen, 1995: Development of lowlevel jets during TAMEX. Mon. Weather Rev., 123, 1695-1719, doi: 10.1175/1520-0493(1995)123<1695: DOLLJD>2.0.CO;2. [Link]

Chen, Y. L. and N. B.-F. Hui, 1990: Analysis of a shallow front during the Taiwan area mesoscale experiment. Mon. Weather Rev., 118, 2649-2667, doi: 10.1175/15 20-0493(1990)118<2649:AOASFD>2.0.CO;2. [Link]

Chen, Y. L. and J. Li, 1995: Large-scale conditions favorable for the development of heavy rainfall during 
TAMEX IOP 3. Mon. Weather Rev., 123, 2978-3002, doi: 10.1175/1520-0493(1995)123<2978:LSCFFT>2.0. $\mathrm{CO} ; 2$. [Link]

Chen, Y. L., Y. X. Zhang, and N. B.-F. Hui, 1989: Analysis of a surface front during the early summer rainy season over Taiwan. Mon. Weather Rev., 117, 909-931, doi: 10.1175/1520-0493(1989)117<0909:AOASFD>2.0. $\mathrm{CO} ; 2$. [Link]

Chi, S. S. and S. A. Huang, 2011: Case study of a heavy rain episode over southern Taiwan during SoWMEX. Conference on Weather Aanlysis, Forecasting and Seismic Observations, Taipei Taiwan, 197-216. (in Chinese)

Dudhia, J., 1989: Numerical study of convection observed during the winter monsoon experiment using a mesoscale two-dimensional model. J. Atmos. Sci., 46, 3077-3107, doi: 10.1175/1520-0469(1989)046<3077: NSOCOD $>2.0 . C O ; 2$. [Link]

Ferrier, B. S., Y. Jin, Y. Lin, T. Black, E. Rogers, and G. DiMego, 2002: Implementation of a new grid-scale cloud and precipitation scheme in the NCEP Eta model. Preprints, $15^{\text {th }}$ Conference on Numerical Weather Prediction, San Antonio, TX, American Meteorological Society, 280-283.

Janjić,Z. I., 1994: The step-mountain eta coordinate model: Further developments of the convection, viscous sublayer, and turbulence closure schemes. Mon. Weather Rev., 122, 927-945, doi: 10.1175/1520-0493(1994)122 $<0927$ :TSMECM>2.0.CO;2. [Link]

Janjić, Z. I., 2000: Comments on "Development and evaluation of a convection scheme for use in climate models." J.Atmos. Sci., 57, 3686, doi: 10.1175/1520-0469(2000) 057<3686:CODAEO>2.0.CO;2. [Link]

Johnson, R. H. and J. F. Bresch, 1991: Diagnosed characteristics of precipitation systems over Taiwan during the May-June 1987 TAMEX. Mon. Weather Rev., 119, 2540-2557, doi: 10.1175/1520-0493(1991)119<2540: DCOPSO $>2.0 . \mathrm{CO} ; 2$. [Link]

Jou, B. J.-D., W. C. Lee, and R. H. Johnson, 2010: An overview of SoWMEX/TiMREX. Selected Papers of the Fourth International Monsoon Workshop, World Scientific, 1-16.

Kuo, Y. H. and G. T.-J. Chen, 1990: The Taiwan area mesoscale experiment (TAMEX): An overview. Bull. Amer. Meteorol. Soc., 71, 488-503, doi: 10.1175/15200477(1990)071<0488:TTAMEA>2.0.CO;2. [Link]

Lai, H. W., C. A. Davis, and B. J.-D. Jou, 2011: A subtropical oceanic mesoscale convective vortex observed during SoWMEX/TiMREX. Mon. Weather Rev., 139, 2367-2385, doi: 10.1175/2010MWR3411.1. [Link]

Li, J., Y. L. Chen, and W. C. Lee, 1997: Analysis of a heavy rainfall event during TAMEX. Mon. Weather Rev., 125, 1060-1082, doi: 10.1175/1520-0493(1997)125<1 060:AOAHRE>2.0.CO;2. [Link]

Lin, Y. J., H. Shen, T.-C. C. Wang, Z. S. Deng, and R. W.
Pasken, 1990: Characteristics of a subtropical squall line determined from TAMEX dual-Doppler data. Part II: Dynamic and thermodynamic structures and momentum budgets. J. Atmos. Sci., 47, 2382-2399, doi: 10.1175/1520-0469(1990)047<2382:COASSL>2.0. $\mathrm{CO} ; 2 .[$ Link $]$

Mlawer, E. J., S. J. Taubman, P. D. Brown, M. J. Iacono, and S. A. Clough, 1997: Radiative transfer for inhomogeneous atmosphere: RRTM, a validated correlated-k model for the longwave. J. Geophys. Res., 102, 1666316682, doi: 10.1029/97JD00237. [Link]

Parrish, D. F. and J. C. Derber, 1992: The national meteorological center's spectral statistical-interpolation analysis system. Mon. Weather Rev., 120, 1747-1763, doi: 10.1175/1520-0493(1992)120<1747:TNMCSS $>2.0$. $\mathrm{CO} ; 2 .[\underline{\mathrm{Link}}]$

Ramage, C. S, 1971: Monsoon Meteorology. International Geophysics Series 15, Academic Press, 296 pp.

Ray, P. S., A. Robinson, and Y. Lin, 1991: Radar analysis of a TAMEX frontal system. Mon. Weather Rev., 119, 2519-2539, doi: 10.1175/1520-0493(1991)119<2519: RAOATF>2.0.CO;2. [Link]

Skamarock, W. C., J. B. Klemp, J. Dudhia, D. O. Gill, D. M. Barker, M. G. Duda, X. Y. Huang, W. Wang, and J. G. Powers, 2008: A Description of the Advanced Research WRF Version 3, NCAR Technical Note, NCAR/ TN-475+STR, 113 pp.

Tao, W. K., J. Simpson, and S. T. Soong, 1991: Numerical simulation of a subtropical squall line over the Taiwan Strait. Mon. Weather Rev., 119, 2699-2723, doi: 10.11 75/1520-0493(1991)119<2699:NSOASS>2.0.CO;2. [Link]

Trier, S. B., D. B. Parsons, and T. J. Matejka, 1990: Observations of a subtropical cold front in a region of complex terrain. Mon. Weather Rev., 118, 2449-2470, doi: 10.1175/1520-0493(1990)118<2449:OOASCF>2.0. $\mathrm{CO} ; 2$. [Link $]$

Wang, T.-C. C., Y. J. Lin, H. Shen, and R. W. Pasken, 1990: Characteristics of a subtropical squall line determined from TAMEX Dual-Doppler data. Part I: Kinematic structure. J. Atmos. Sci., 47, 2357-2381, doi: 10.117 5/1520-0469(1990)047<2357:COASSL>2.0.CO;2. [Link]

Wilks, D. S., 2006: Statistical Methods in the Atmospheric Sciences. Academic Press, 627 pp.

Xiao, Q. and J. Sun, 2007: Multiple-radar data assimilation and short-range quantitative precipitation forecasting of a squall line observed during IHOP_2002. Mon. Weather Rev., 135, 3381-3404, doi: 10.1175/MWR34 71.1. [Link]

Xiao, Q., X. Zhang, C. Davis, J. Tuttle, G. Holland, and P. J. Fitzpatrick, 2009: Experiments of hurricane initialization with airborne Doppler radar data for the Advanced-research Hurricane WRF (AHW) model. Mon. 
Weather Rev., 137, 2758-2777, doi: 10.1175/2009MW R2828.1. [Link]

Yeh, H. C., 2010: Application of satellite-derived ocean surface winds to the detection of weather systems and the prediction of near-ocean surface winds around Hawaii. Terr. Atmos. Ocean. Sci., 21, 955-969, doi: 10.3319/ TAO.2010.03.29.01(A). [Link]

Yeh, H. C. and Y. L. Chen, 1998: Characteristics of rainfall distributions over Taiwan during the Taiwan Area Mesoscale Experiment (TAMEX). J. Appl. Meteorol., 37, 1457-1469, doi: 10.1175/1520-0450(1998)037<1457: CORDOT>2.0.CO;2. [Link]

Yeh, H. C. and Y. L. Chen, 2002: The role of offshore con- vergence on coastal rainfall during TAMEX IOP 3 . Mon. Weather Rev., 130, 2709-2730, doi: 10.1175/152 0-0493(2002)130<2709:TROOCO > 2.0.CO;2. [Link]

Yeh, H. C. and G. T.-J. Chen, 2004: Case study of an unusually heavy rain event over Eastern Taiwan during the Mei-yu season. Mon. Weather Rev. 132, 320-337, doi: 10.1175/1520-0493(2004)132<0320:CSOAUH $>2.0$. CO;2. [Link]

Yeh, H. C., G. T.-J. Chen, and W. T. Liu, 2002: Kinematic characteristics of a Mei-yu front detected by the QuikSCAT oceanic winds. Mon. Weather Rev., 130, 700711, doi: 10.1175/1520-0493(2002)130<0700:KCOA MY>2.0.CO;2. [Link] 